ARTICLE OPEN

\title{
Chemical characterisation of degraded nuclear fuel analogues simulating the Fukushima Daiichi nuclear accident
}

Hao Ding ${ }^{1}$, Clémence Gausse ${ }^{1}$, Malin C. Dixon Wilkins ${ }^{1}$, Lucy M. Mottram ${ }^{1}$, Martin C. Stennett (iD) ${ }^{1}$ Daniel Grolimund (iD ${ }^{2}$, Ryan Tappero ${ }^{3}$, Sarah Nicholas $\mathbb{D i}^{3}$, Shikuan Sun ${ }^{1,4}$, Tomooki Shiba ${ }^{5}$, C. Paraskevoulakos ${ }^{6}$, Neil C. Hyatt $\mathbb{D}^{1 凶}$ and Claire L. Corkhill $\mathbb{D}^{1 凶}$

The Fukushima Daiichi accident generated degraded nuclear fuel material, mixed with other reactor components, known as molten coreconcrete interaction $(\mathrm{MCCl})$ material. Simulant $\mathrm{MCCl}$ material was synthesised, excluding highly radioactive fission products, containing depleted $\mathrm{U}$, and incorporating $\mathrm{Ce}$ as a surrogate for $\mathrm{Pu}$. Multi-modal $\mu$-focus $\mathrm{X}$-ray analysis revealed the presence of the expected suite of $\mathrm{U}-\mathrm{Zr}-\mathrm{O}$ containing minerals, in addition to crystalline silicate phases $\mathrm{CaSiO}_{3}, \mathrm{SiO}_{2}$-cristobalite and $\mathrm{Ce}$-bearing percleveite, $(\mathrm{Ce}, \mathrm{Nd})_{2} \mathrm{Si}_{2} \mathrm{O}_{7}$. The formation of perclevite resulted from reaction between the $\mathrm{U}-\mathrm{Zr}$-O-depleted $\mathrm{Ce}-\mathrm{Nd}-\mathrm{O}$ melt and the silicate $\left(\mathrm{SiO}_{2}\right) \mathrm{melt}_{\text {. It }}$ was determined that the majority of $\mathrm{U}$ was present as $\mathrm{U}^{4+}$, whereas $\mathrm{Ce}$ was observed to be present as $\mathrm{Ce}^{3+}$, consistent with the highly reducing synthesis conditions. A range of Fe-containing phases characterised by different average oxidation states were identified, and it is hypothesised that their formation induced heterogeneity in the local oxygen potential, influencing the oxidation state of Ce.

npj Materials Degradation (2022)6:10; https://doi.org/10.1038/s41529-022-00219-3

\section{INTRODUCTION}

The Fukushima Daiichi nuclear power plant (1F) experienced a loss of coolant accident on 11 March 2011 as a result of the Great East Japan earthquake and resultant tsunami. Three of the reactor cores experienced meltdown (units 1,2 and 3) and hydrogen explosions resulted in the release of radionuclides to the surrounding area ${ }^{1,2}$. Within the reactor cores, overheating led to melting of fuel pellets $\left(\mathrm{UO}_{2}\right.$ and $\left.(\mathrm{U}, \mathrm{Pu}) \mathrm{O}_{2}\right)$ and fuel cladding (zircaloy), as well as other core materials such as control rods (stainless steel and $\mathrm{B}_{4} \mathrm{C}$ ). A portion of the melted core materials are expected to have penetrated the bottom of the reactor pressure vessel, further reacting with concrete and forming molten core-concrete interaction (MCCl) products ${ }^{3}$, analogous to the lava-like fuel containing materials (LFCM) present at Reactor 4 of the Chernobyl nuclear power plant ${ }^{4-7}$. Understanding the chemical and physical properties of $\mathrm{MCCl}$ is of significant importance for the retrieval, storage and disposal of these severely damaged nuclear materials.

Samples of $\mathrm{MCCl}$ from $1 \mathrm{~F}$ are yet to be collected due to the extreme radioactivity still present and the operational challenges associated with utilisation of robotic sampling techniques. In the absence of such material, simulations of the core melting process and thermodynamic modelling techniques have been conducted to predict the composition of the solidified phases under $1 \mathrm{~F}$ accident conditions $\mathrm{s}^{3,8,9}$. For example, VULCANO and VESTA have been utilised to investigate the formation and microstructure of $\mathrm{MCCl}^{10-12}$. While such large-scale experiments provide beneficial insight, they are challenging to replicate due to their high cost and hazard. These experiments have, thus far, not investigated $\mathrm{MCCl}$ incorporating plutonium, or its surrogates (e.g. $\mathrm{Ce}, \mathrm{Hf}, \mathrm{Nd}$ ). This is of particular relevance to $1 \mathrm{~F} \mathrm{MCCl}$ since a portion of the fuel within Unit 3 at the time of the accident was mixed oxide $\left[(U, P u) O_{2}\right]$ fuel.

To gain insight into the chemical distribution and speciation of $\mathrm{U}$ and $\mathrm{Pu}$ within $\mathrm{MCCl}$, and the phase assemblage, a suite of low-radioactivity simulant Fukushima $\mathrm{MCCl}$ materials, containing $\mathrm{Ce}$ as a surrogate for $\mathrm{Pu}$, were synthesised and characterised at laboratory scale. Ce has been widely applied as an inactive surrogate for $\mathrm{Pu}$ due to similarities in available oxidation states, chemical behaviour under conditions of ceramic synthesis, and electronic structure $\left(\mathrm{Ce}^{4+}\right.$ ionic radius $0.97 \AA$ vs $\mathrm{Pu}^{4+}$ ionic radius $0.96 \AA)^{13,14}$. The behaviour of $\mathrm{Ce}$ in the simulant $\mathrm{MCCl}$ products can provide potential insight towards the behaviour of $\mathrm{Pu}$ in the real $\mathrm{MCCl}$ materials; although there are some differences between $\mathrm{Pu}$ and $\mathrm{Ce}$, such as the ability of $\mathrm{Ce}^{4+}$ to be reduced to $\mathrm{Ce}^{3+}$ in zirconbased ceramics, whereas, in contrast, Pu does not readily reduce ${ }^{15}$. In this study, Nd was chosen to be representative of the trivalent rare earth elements, present in the $\mathrm{MCCl}$ as fission products. While no real material is available with which to verify the similarity of the simulant to Fukushima $\mathrm{MCCl}$, the synthesis methods of this study are based on those of previous work on Chernobyl LFCM simulants, which closely resembled real LFCM obtained from within the reactor $^{16,17}$. Several approaches were trialled to incorporate the $\mathrm{Pu}$ surrogate, $\mathrm{Ce}$, and bulk analysis of the resulting simulant $\mathrm{MCCl}$ is presented. Synchrotron multi-modal $\mu$-focus $X$-ray analyses were further conducted to derive detailed insight to the simulant $\mathrm{MCCl}$ materials. Micron-resolved chemical probes (X-ray fluorescence, $\mu$-XRF and X-ray Absorption Spectroscopy, $\mu$-XAS) and diffraction analysis ( $\mu$-XRD) were combined to identify the crystalline phases and to determine the local $\mathrm{U}$ and Ce chemistry in both crystalline and amorphous phases.

\section{RESULTS AND DISCUSSION Bulk characterisation of $\mathrm{MCCl}$ simulants}

The batched compositions of simulant MCCI materials were based on estimations of the relative proportions of core materials and concrete, previously reported in the literature and through

\footnotetext{
${ }^{1}$ NucleUS Immobilisation Science Laboratory, Department of Materials Science and Engineering, The University of Sheffield, Sheffield S1 3JD, UK. ${ }^{2}$ Swiss Light Source, Paul Scherrer Institut, 5232 Villigen PSI, Switzerland. ${ }^{3}$ Brookhaven National Laboratory, NSLS-II, Upton, NY 11973, USA. ${ }^{4}$ School of Material Science and Energy Engineering, Foshan

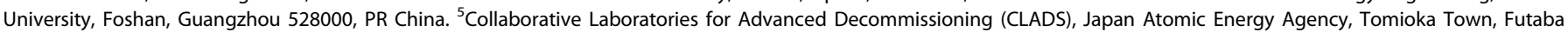
County, Fukushima 979-1151, Japan. ${ }^{6}$ Interface Analysis Centre, School of Physics, University of Bristol, Bristol BS8 1TL, UK. ${ }^{凶}$ email: n.c.hyatt@sheffield.ac.uk; c.corkhill@sheffield.ac.uk
} 
Table 1. As batched compositions of simulant $\mathrm{MCCl}$ materials.

\begin{tabular}{llll}
\hline Component & $\mathrm{MCCl}-1$ (mol.\%) & $\mathrm{MCCl}-2$ (mol.\%) & $\mathrm{MCCl}-3$ (mol.\%) \\
\hline $\mathrm{SiO}_{2}$ & 31.26 & 30.90 & 31.93 \\
$\mathrm{CaO}$ & 5.94 & 5.87 & 6.04 \\
$\mathrm{Al}_{2} \mathrm{O}_{3}$ & 13.11 & 12.96 & 13.39 \\
$\mathrm{Fe}_{2} \mathrm{O}_{3}$ & 7.96 & 7.87 & 8.15 \\
316 Stainless steel & 1.12 & 1.11 & 1.16 \\
$\mathrm{ZrO}_{2}$ & - & 6.71 & 6.84 \\
$\mathrm{U}_{0.6} \mathrm{Zr}_{0.4} \mathrm{O}_{2}$ & 28.37 & - & - \\
$\mathrm{U}_{0.9} \mathrm{Ce}_{0.1} \mathrm{O}_{2}$ & 6.12 & - & - \\
$\mathrm{U}_{0.9} \mathrm{Nd}_{0.1} \mathrm{O}_{2}$ & 6.12 & - & - \\
$\mathrm{U}_{0.9} \mathrm{Ce}_{0.05} \mathrm{Nd}_{0.05} \mathrm{O}_{2}$ & - & 34.58 & - \\
$\mathrm{U}_{0.9} \mathrm{Ce}_{0.05} \mathrm{Zr}_{0.05} \mathrm{O}_{2}$ & - & - & 32.49 \\
$\mathrm{Total}$ & 28.04 & 31.12 & 29.24 \\
Total $\mathrm{Ce}$ & 1.22 & 1.73 & 1.62 \\
Total $\mathrm{Zr}$ & 11.35 & 6.71 & 8.46 \\
TOTAL & 100.00 & 100.00 & 100.00 \\
\hline
\end{tabular}

discussion with personnel at the Japan Atomic Energy Agency Collaborative Laboratories for Advanced Decommissioning Science $(\mathrm{CLADS})^{8,18}$. In all compositions, the content of concrete forming oxides $\left(\mathrm{SiO}_{2}, \mathrm{CaO}\right.$ and $\left.\mathrm{Al}_{2} \mathrm{O}_{3}\right)$ and stainless steel components $\left(\mathrm{Fe}_{2} \mathrm{O}_{3}\right.$ and 316 stainless steel filings) were kept constant, while the method of Pu surrogate $(\mathrm{Ce})$ and $\mathrm{Zr}$ addition was varied (Table 1). Previous studies of degraded nuclear fuel simulants incorporated $\mathrm{Zr}$ simply as $\mathrm{Zr}$ and/or $\mathrm{ZrO}_{2}{ }^{10,19}$. However, since $\mathrm{U}, \mathrm{Pu}$ and $\mathrm{Zr}$ would have been in a U-Pu-Zr-O solid solution at the point at which the molten degraded fuel contacted other reactor components including stainless steel and concrete, these elements were added to the simulant $\mathrm{MCCl}$ as various $\left(\mathrm{U}_{1-\mathrm{x}-\mathrm{y}} \mathrm{Ce}_{\mathrm{x}} \mathrm{Zr}_{\mathrm{y}}\right) \mathrm{O}_{2-\delta}$ oxide materials. The microstructure and phase assemblage of these materials is described in Supplementary Fig. 1 . Since the $\mathrm{B}_{4} \mathrm{C}$ control rods are expected to be a small fraction of the overall $\mathrm{MCCl}$ inventory, and because the influence of carbide on $\mathrm{MCCl}$ composition is small, the $\mathrm{MCCl}$ simulants in this study did not incorporate $\mathrm{B}_{4} \mathrm{C}$.

Analysis of the simulant $\mathrm{MCCl}$ materials revealed a microstructure and mineralogy broadly consistent with large-scale simulation experiments (e.g. VULCANO), thermodynamic modelling and Chernobyl LFCM $4,8,19,20$. The presence of a glass phase containing crystallite inclusions was confirmed for all three $\mathrm{MCCl}$ materials by XRD (Fig. 1), with a region of diffuse scattering present between $15^{\circ}<2 \theta<35^{\circ}$ and identifiable Bragg reflections in all diffraction patterns. As expected, uranium-rich cubic c-(U,Zr)O $\mathrm{O}_{2}$ (PDF 04-0194898), zircon ( $\left.\mathrm{ZrSiO}_{4} ; \mathrm{PDF} 00-033-1485\right]$ and anorthite $\left(\mathrm{CaAl}_{2} \mathrm{Si}_{2} \mathrm{O}_{8}\right.$; PDF 01-076-0948) were identified in all three $\mathrm{MCCl}$ compositions. Although the batched compositions of each $\mathrm{MCCl}$ simulant were similar, there were subtle differences in the remainder of the phase assemblage. The addition of $\mathrm{Zr}$ as $\mathrm{ZrO}_{2}$, in $\mathrm{MCCl}-2$ and $\mathrm{MCCl}-3$ only, was associated with the identification of monoclinic $\mathrm{ZrO}_{2}$ (PDF 04-008-7681). The additional $\mathrm{ZrO}_{2}$ also appeared to promote the formation of zircon and anorthite, with the reflections indexed to these phases higher in relative intensity in the diffraction patterns of $\mathrm{MCCl}-2$ and $\mathrm{MCCl}-3$. Reflections indexed as Fe-Ni (PDF 00-047-1405) were observed in all samples except $\mathrm{MCCl}-1$, which may be due to a heterogenous oxygen potential within the sample (see below).

The presence of each of these phases was confirmed by SEM/ EDS of each MCCI material, as shown in Fig. 2. c- $(\mathrm{U}, \mathrm{Zr}) \mathrm{O}_{2}$ and $\mathrm{U}-\mathrm{Zr}$ O crystallites (see Supplementary Fig. 2) were observed in several typical morphologies. The microstructure of $\mathrm{MCCl}-1$ (see Fig. 2a) showed $\mathrm{c}-(\mathrm{U}, \mathrm{Zr}) \mathrm{O}_{2}$ present as prismatic crystallites, in some

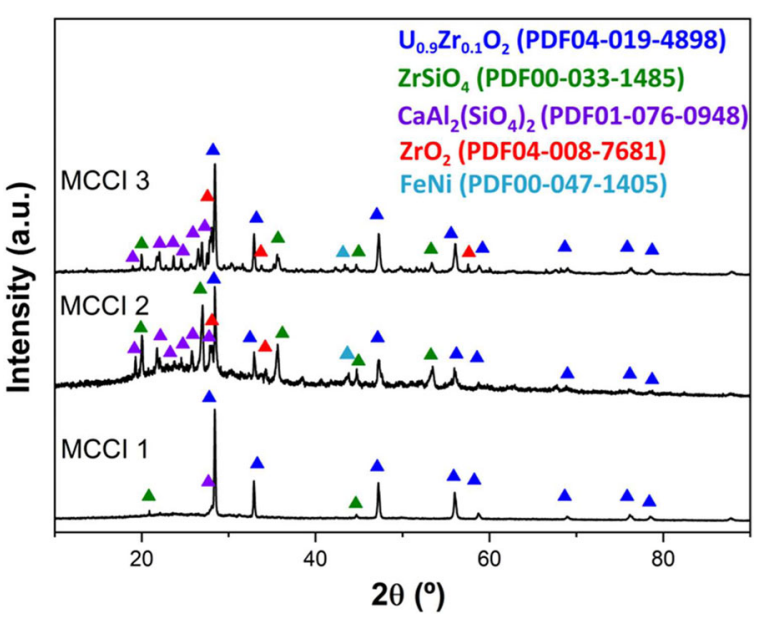

Fig. 1 X-ray diffraction data obtained for each of the three MCCI simulants.

regions contacting with zircon crystalline phases surrounded by anorthite, with the Ca-aluminosilicate glass (see Supplementary Fig. 2) forming the surrounding matrix.

Fused and dendritic morphologies were observed in $\mathrm{MCCl}-2$ and MCCI-3 (see Fig. 2b, c, respectively). It is possible that $U$ was also incorporated into the zircon phase, as shown by the EDS spectrum in Fig. $2 d$, although it is possible that the EDS oversampled the crystallite and measured underlying $\mathrm{U}$-containing phases. The other main segregated silicate phase contained $\mathrm{Al}, \mathrm{Ca}$ and $\mathrm{Fe}$ (Fig. 2e), suggestive of Fe-bearing anorthite, in agreement with XRD data. EDS data averaged over several anorthite crystallites gave an approximate composition of $\mathrm{Ca}\left(\mathrm{Al}_{0.9} \mathrm{Fe}_{1.1}\right)_{2} \mathrm{Si}_{2} \mathrm{O}_{8}$, showing a significant substitution of Fe by Al. It was not possible to discern the distribution of the Pu surrogate, $\mathrm{Ce}$, by EDS due to the low concentration (Supplementary Fig. 2).

\section{Phase assemblage determination by $\boldsymbol{\mu}$-focus $\mathrm{X}$-ray analysis}

To complement the bulk analyses and obtain high resolution, spatially resolved characterisation, the phase assemblages of the three $\mathrm{MCCl}$ samples were also determined by microanalysis. The chemical composition and corresponding $\mu$-XRD analysis of a representative area of $\mathrm{MCCl}-1$ are shown in Fig. 3. Individual $\mu$-XRD patterns are given in Supplementary Material Fig. 3. U-rich, $\mathrm{Zr}$ containing crystallites (generally within the size range $5-25 \mu \mathrm{m}$ ) were indexed as cubic $\mathrm{Zr}$-containing $\mathrm{UO}_{2}\left(\mathrm{c}-\left(\mathrm{U}_{1-\mathrm{x}} \mathrm{Zr}_{\mathrm{x}}\right) \mathrm{O}_{2}\right.$; PDF 04019-4898), consistent with the bulk analysis (Figs. 1 and 2). This was the major phase present in the region of interest; however, other phases were identified; including tetragonal U-containing $\mathrm{ZrO}_{2}(\mathrm{t}-$ $\left(\mathrm{U}_{1-\mathrm{x}} \mathrm{Zr}_{\mathrm{x}}\right) \mathrm{O}_{2}$; PDF 04-020-6305) and monoclinic $\mathrm{ZrO}_{2}$, both with and without significant $\mathrm{U}\left(\left(\mathrm{m}-\left(\mathrm{Zr}_{1-\mathrm{x}} \mathrm{U}_{\mathrm{x}}\right) \mathrm{O}_{2}\right)\right.$ and $\mathrm{m}-\mathrm{ZrO}_{2}$; PDF 04-0087681; respectively). These phases were clustered around crystallites of $c-\left(U_{1-x} Z_{x}\right) O_{2}$, forming fused aggregates. The spatial correlation of $\mathrm{U}$ and $\mathrm{Zr}$ (Supplementary Fig. 4), and the corresponding distribution of phases, are in good agreement with the previous microanalysis of simulant Chernobyl LFCM ${ }^{17}$.

Also, in agreement with the bulk characterisation (Fig. 2a, b), silicate crystalline phases indexed as anorthite $\left(\mathrm{CaAl}_{2} \mathrm{Si}_{2} \mathrm{O}_{8}\right.$; PDF 01-076-0948) and wollastonite $\left(\mathrm{CaSiO}_{3}\right.$; PDF 00-027-0088), were found to surround the fused U-Zr-O crystallites (Fig. 3c). Minor amounts of $\mathrm{SiO}_{2}\left(\mathrm{SiO}_{2}\right.$-quartz; PDF 00-046-1045) were present $(2-5 \mu \mathrm{m})$, trapped between $\mathrm{c}-\left(\mathrm{U}_{1-\mathrm{x}} \mathrm{Zr}_{\mathrm{x}}\right) \mathrm{O}_{2}$ and $\mathrm{CaAl}_{2} \mathrm{Si}_{2} \mathrm{O}_{8}$ crystallites. This is most likely unreacted $\mathrm{SiO}_{2}$. Metallic $\mathrm{Fe}-\mathrm{Ni}$ alloy particles (Fe-Ni; PDF 00-047-1405) were found in the regions of highest Fe and Ni concentration, as determined by XRF maps of elemental distribution shown in Supplementary Fig. 4. Originating from stainless steel and $\mathrm{Fe}_{2} \mathrm{O}_{3}$ in the initial batched material, 

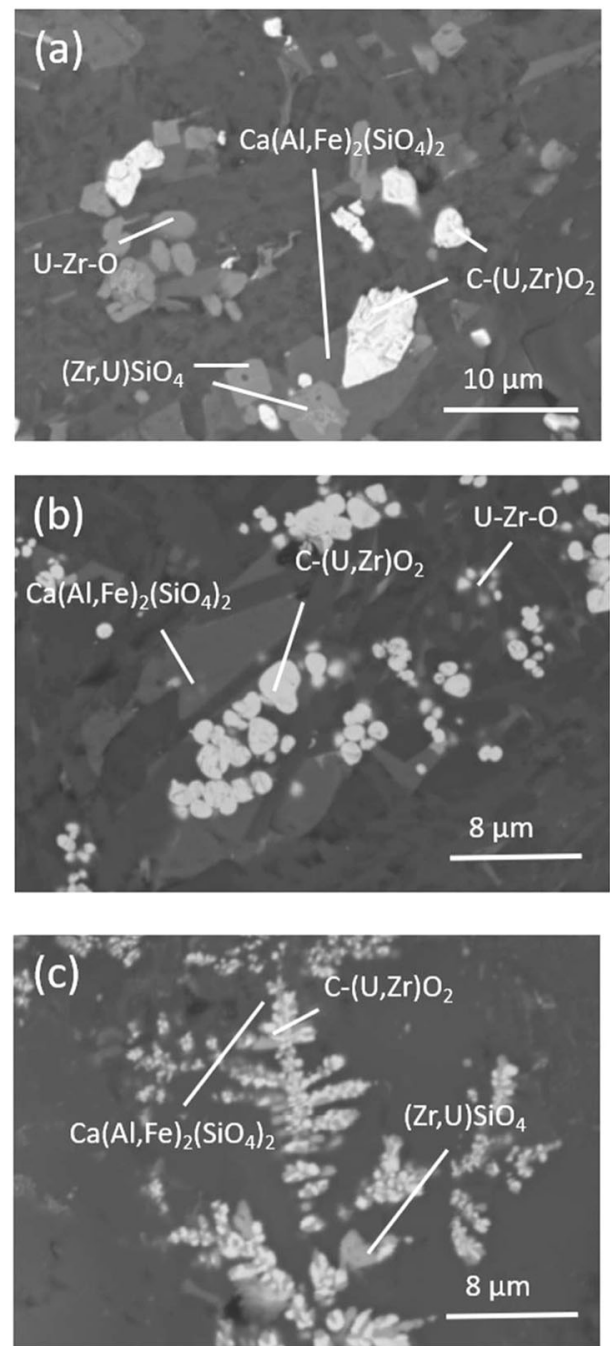

Fig. 2 SEM images and EDS spectra of simulant $\mathrm{MCCl}$ materials. Showing a $\mathrm{MCCl}-1, \mathbf{b} \mathrm{MCCl}-2$ and $\mathbf{c} \mathrm{MCCl}-3$; and EDS spectra of $\mathbf{d}$ uraniumcontaining zircon and e the Al-Ca-Fe rich silicate phase, identified by XRD as anorthite. Scale bars are as follow: $\mathbf{a} 10 \mu \mathrm{m} ; \mathbf{b} 8 \mu \mathrm{m} ;$ and $\mathbf{c} 8 \mu \mathrm{m}$.

several small $(2-4 \mu \mathrm{m}) \mathrm{Fe}$ oxides were identified, including $\mathrm{FeCr}_{2} \mathrm{O}_{4}$ [PDF 04-006-2807], $\mathrm{Fe}_{2} \mathrm{O}_{3}$ [PDF 01-076-4579] and $\mathrm{Fe}_{3} \mathrm{O}_{4}$ [PDF 01-075-0449], as shown in Supplementary Fig. 4. Since the intensities of the XRD reflections of these phases are much lower than the dominant phases present at the same pixels, they are not visible in the $\mu$-XRD map shown in Fig. 3c. The presence of Fephases bearing different oxidation states of $\mathrm{Fe}$, given the highly reducing conditions of the synthesis, points to localised differences in the redox conditions during the MCCI synthesis. The observed crystalline phases were embedded within a calcium-rich aluminosilicate glass matrix.

MCCl-2 presented a similar phase assemblage, but with a larger range of crystalline phases identified, as shown in Fig. 4. This is attributed to differences in the as-batched compositions, and was confirmed by comparison of the $\mu$-XRF spectra (Fig. 4a) of MCCl-1 and $\mathrm{MCCl}-2$ : the intensities of $\mathrm{Ce}-\mathrm{La}$ and $\mathrm{Zr}-\mathrm{Ka}$ compared to the Fe-Ka emission (which was essentially unchanged) show variations between the two compositions. For example, the relative intensity of Ce-La of MCCl-2 was higher and Zr-Ka was lower when compared to $\mathrm{MCCl}-1$, matching well with the batch composition (Table 1). Due to the greater quantity of $\mathrm{ZrO}_{2}$ added to the $\mathrm{MCCl}-2$ batch, an additional $\mathrm{Zr}$-containing phase, zircon $\left[\mathrm{ZrSiO}_{4}\right.$; PDF 00 033-1485], was observed at the edge of the regions of fused morphology. Some crystallites of zircon also contained $U$ and/or $\mathrm{Ce}$, as observed in the XRF maps of $\mathrm{U}, \mathrm{Ce}$, and Zr (Fig. 4b-d).
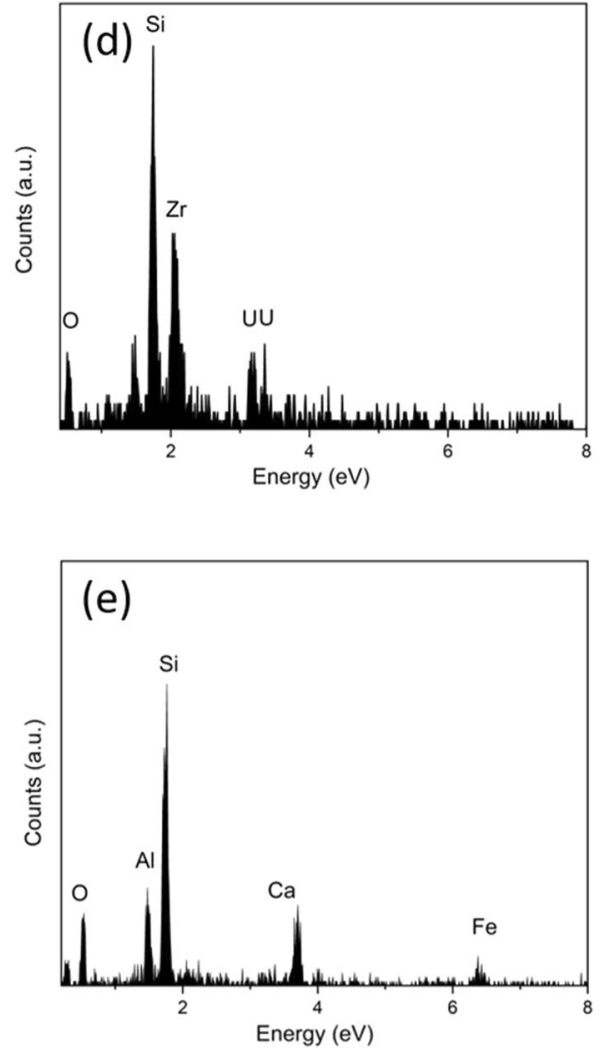

Ce-doped zircon has been synthesised and widely investigated by previous studies to simulate and understand the properties of $\mathrm{Pu}$-doped zircon, but has not been reported within simulant $\mathrm{MCCl}$ products ${ }^{21,22}$. As both $\mathrm{Ce}^{3+}$ and $\mathrm{Ce}^{4+}$ can exist in zircon, examination of the oxidation states of $\mathrm{Ce}$ is of interest, and could give important insight to material interactions during $\mathrm{MCCl}$ formation and $\mathrm{Pu}$ redox behaviours. Under reduced atmosphere, $\mathrm{Pu}^{4+}$ in the $\mathrm{Pu}-\mathrm{Si}-\mathrm{O}$ system can be reduced to $\mathrm{Pu}^{3+}$ in the form of $\mathrm{Pu}_{4.67} \mathrm{Si}_{3} \mathrm{O}_{13}$ and $\mathrm{Pu}_{2} \mathrm{Si}_{2} \mathrm{O}_{7}{ }^{23}$. Small crystallites of $\mathrm{SiO}_{2}\left(\mathrm{SiO}_{2-}\right.$ cristobalite; PDF 00-039-1425), with approx. sizes in the range $2-5 \mu \mathrm{m}$, were observed in the vicinity of zircon (see Fig. 4c) inclusions. Ce-rich, $\mathrm{Nd}$-containing crystallites were identified and indexed as $\mathrm{Nd}$-doped $\mathrm{Ce}_{2} \mathrm{Si}_{2} \mathrm{O}_{7}$ (percleveite, $(\mathrm{Ce}, \mathrm{Nd})_{2} \mathrm{Si}_{2} \mathrm{O}_{7}$; PDF 00048-1588).

The elemental distributions of $\mathrm{U}, \mathrm{Zr}, \mathrm{Ce}$ and $\mathrm{Fe}$ of $\mathrm{MCCl}-3$ are displayed in Fig. 5. Ce was distributed similarly to $U$ and $Z r$, present in both the glassy matrix and $\mathrm{U}$-Zr-O-containing crystallites. However, it also appeared that some $\mathrm{Ce}$ was also concentrated in the vicinity of Fe-enriched regions, and was concentrated in the interiors of pores.

\section{MCCI silicate and iron-phase mineralogy}

The concrete within $1 \mathrm{~F}$ was particularly silica-rich, due to the presence of sand as a mortar binder. Thermodynamic analysis of 

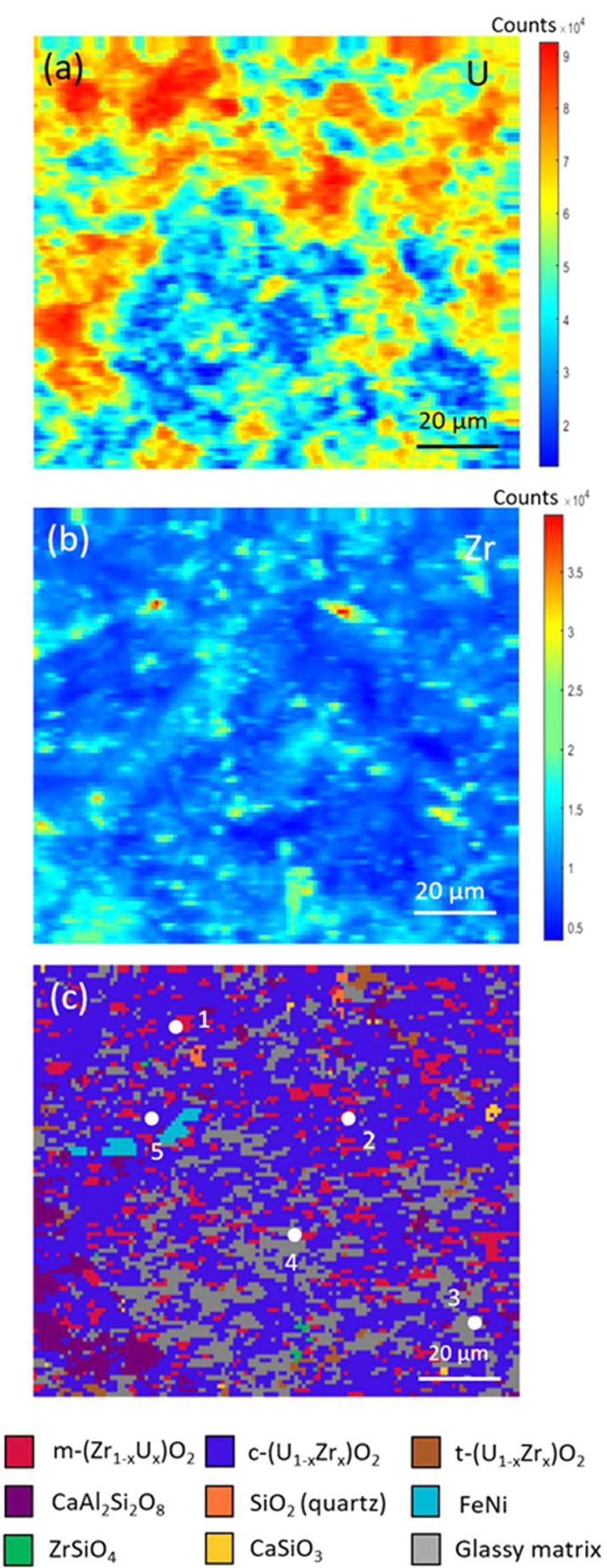

Fig. 3 Micro-focus X-ray analysis of $\mathrm{MCCl}-1$. Showing distribution of a U-L $\alpha$ and $\mathbf{b} \mathrm{Zr}-\mathrm{K} \alpha$ X-ray fluorescence signals; and c $2 \mathrm{D} \mu$ diffraction map reconstructed from $\mu$-XRD patterns taken at each pixel in the $\mu$-XRF maps shown in $\mathbf{a}$ and $\mathbf{b}$. The individual XRD patterns are shown in Fig. 6 and Supplementary Figs. 3 and 4. The white points labelled $1-5$ in $c$ indicate the locations of interest that XANES spectra were collected from, detailed in Fig. 7. Scale bar on all images is $20 \mu \mathrm{m}$.

materials within the $1 \mathrm{~F}$ accident, performed by Kitagaki et al. ${ }^{4}$, predicted that zircon $\left(\mathrm{ZrSiO}_{4}\right)$ should be formed in $\mathrm{MCCl}$ from the interaction of molten fuel with silica in concrete, but not in significant quantities since it requires a relatively long time to crystallise $^{24}$. The rapid quenching of the molten material in $1 \mathrm{~F}$ by seawater was predicted to have cooled the degraded fuel quickly, promoting the formation of other silicate minerals including anorthite $\left(\mathrm{CaAl}_{2} \mathrm{Si}_{2} \mathrm{O}_{8}\right)$ and wollastonite $\left(\mathrm{CaSiO}_{3}\right)$. These phases are identified in the $\mathrm{MCCl}$ simulants in the present study, which suggest that the synthesis method and, in particular, the cooling profile, represents conditions relevant to stages of $1 \mathrm{~F}$ $\mathrm{MCCl}$ formation.

Single-pixel $\mu$-XRD patterns of the silicate minerals were strongly influenced by preferred crystallographic orientation (see Supplementary Fig. 5); consequently, only a few of the expected reflections are observed at any one pixel. Nevertheless, it was possible to identify single-pixel $\mu$-XRD patterns consistent with anorthite, wollastonite, $\mathrm{SiO}_{2}$-quartz and $\mathrm{SiO}_{2}$-cristobalite (Fig. 6).

Crystallites of anorthite were found to envelop $\left(U_{1-x} Z_{x}\right) O_{2}$ aggregates within the glassy matrix, indicating that formation of anorthite was associated with the Si-rich region at the interface of the U-Zr-O melt and silicate melt (Fig. 2a, b). A similar solidified silicate phase, containing $\mathrm{Zr}$ in addition to $\mathrm{Ca}, \mathrm{Al}, \mathrm{Si}$ and $\mathrm{O}-$ rankinite $\left((\mathrm{Ca}, \mathrm{Al}, \mathrm{Zr})_{3} \mathrm{Si}_{2} \mathrm{O}_{7}\right)$ - was identified by EDS and WDS analyses reported in a previous study of the U-Zr-Al-Ca-Si-O system $^{25}$ and, in the same study, was also observed to surround crystallites of Ca-containing $(\mathrm{U}, \mathrm{Zr}) \mathrm{O}_{2}$. Based on analysis of phase equilibria for various molten nuclear fuel/cladding and cement phases, the formation of anorthite is favoured over rankinite at high $\mathrm{UO}_{2} / \mathrm{ZrO}_{2}$ ratios ${ }^{26}$.

Wollastonite $\left(\mathrm{CaSiO}_{3}\right)$ was rarely detected in $\mathrm{MCCl}-1$, but was observed to be more abundant in $\mathrm{MCCl}-2$, where zircon was also more abundant. According to the $\mathrm{CaO}-\mathrm{SiO}_{2}-\mathrm{Al}_{2} \mathrm{O}_{3}$ ternary phase diagram, wollastonite is the solidified phase most preferable to form at low Al concentrations ${ }^{26}$. Crystallites of wollastonite were most commonly located at the edge of the fused aggregates of $\mathrm{U}-\mathrm{Zr}-\mathrm{O}$ phases; the appearance of wollastonite reflections being accompanied by several other phases such as $\mathrm{CaAl}_{2} \mathrm{Si}_{2} \mathrm{O}_{8}$, $\mathrm{m}-\left(\mathrm{Zr}_{1-\mathrm{x}} \mathrm{U}_{\mathrm{x}}\right) \mathrm{O}_{2}, \mathrm{c}-\left(\mathrm{U}_{1-\mathrm{x}} \mathrm{Zr}_{\mathrm{x}}\right) \mathrm{O}_{2}$ and $\mathrm{FeCr}_{2} \mathrm{O}_{4}$ (Fig. 6a) further indicating the heterogeneous nature of the $\mathrm{U}-\mathrm{Zr}-\mathrm{O}$ melt and silicate melt interface. Cristobalite-SiO $\mathrm{S}_{2}$ crystallites were also closely associated with zircon, though tended to be located in regions of glass matrix that were depleted in $\mathrm{Zr}$. This is in good agreement with previous thermodynamic evaluations of similar chemical systems ${ }^{8}$. Quartz$\mathrm{SiO}_{2}$, unlike cristobalite- $\mathrm{SiO}_{2}$, was found to be randomly distributed within $\mathrm{MCCl}-1$ and $\mathrm{MCCl}-2$, and is likely a relic of unreacted reagents.

$\mathrm{MCCl}-2$ exhibited coexistence of an Fe-Ni metallic phase and $\mathrm{Fe}^{2+} \mathrm{Cr}_{2} \mathrm{O}_{4}$ indicating that this analysed region formed under a low local oxygen potential. In comparison, the majority of Fecontaining regions in $\mathrm{MCCl}-1$ were composed of three different oxides $\left(\mathrm{FeCr}_{2} \mathrm{O}_{4}, \mathrm{Fe}_{3} \mathrm{O}_{4}\right.$ and $\left.\mathrm{Fe}_{2} \mathrm{O}_{3}\right)$ suggesting a higher local oxygen potential during phase formation. The presence of Fecontaining oxides was attributed to reactions between stainless steel and $\mathrm{SiO}_{2}{ }^{8}$. This variation in phases present is in agreement with the established redox behaviour of metallic $\mathrm{Fe}$ and $\mathrm{Cr}$ (initially present as 316 stainless steel, $\mathrm{Fe} / \mathrm{Cr}_{18} / \mathrm{Ni}_{10} / \mathrm{Mo}_{3}$ ). First, the spinel-structured $\mathrm{Fe}^{2+} \mathrm{Cr}_{2} \mathrm{O}_{4}$ formed on oxidation of $\mathrm{Cr}\left(\mathrm{Cr}\right.$ to $\left.\mathrm{Cr}^{3+}\right)$ and some $\mathrm{Fe}\left(\mathrm{Fe}\right.$ to $\mathrm{Fe}^{2+}$ ), followed by further oxidation of $\mathrm{Fe}$, forming the higher oxides $\mathrm{Fe}_{3} \mathrm{O}_{4}$ and $\mathrm{Fe}_{2} \mathrm{O}_{3}$.

\section{Local coordination chemistry of $\mathbf{U}$ in simulant $\mathbf{M C C l}$}

Points representative of the different $U$ phases present were selected (see numbered points in Figs. $3 c$ and $4 c$ ) and analysed by $U L_{3}$ edge $\mu$-X-ray Absorption Near Edge Spectroscopy ( $\mu$-XANES). The average oxidation state at each point was determined by examining the energy position of the $\mu$-XANES spectra, utilising a suite of uranium-containing compounds of known oxidation state and local coordination for comparison. The data are shown in Fig. 7.

The $U L_{3} \mu$-XANES spectra of points taken in regions identified as $\mathrm{m}-\left(\mathrm{Zr}_{1-\mathrm{x}} \mathrm{U}_{\mathrm{x}}\right) \mathrm{O}_{2}$ (point 1$), \mathrm{t}-\left(\mathrm{Zr}_{1-\mathrm{x}} \mathrm{U}_{\mathrm{x}}\right) \mathrm{O}_{2}$ (point 2 ), and $\mathrm{c}-\left(\mathrm{U}_{1-\mathrm{x}} \mathrm{Zr} \mathrm{r}_{\mathrm{x}}\right)$ $\mathrm{O}_{2}$ (points 4,5 and 7 ) were essentially identical to the spectrum of 

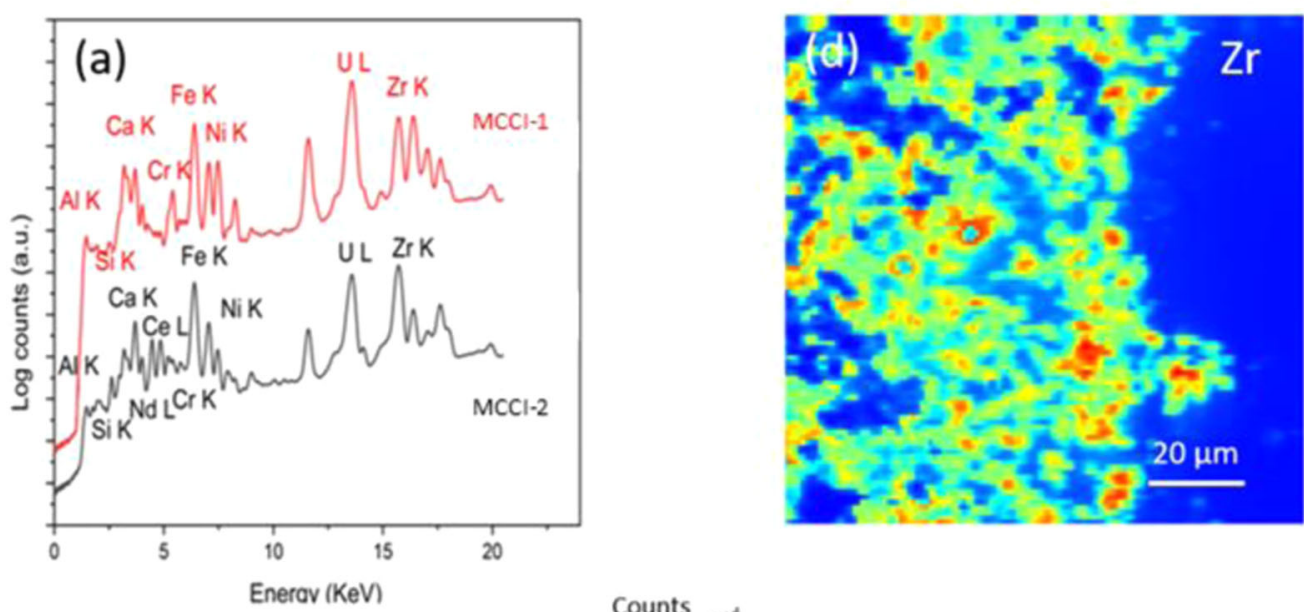

Counts $\times 10^{4}$
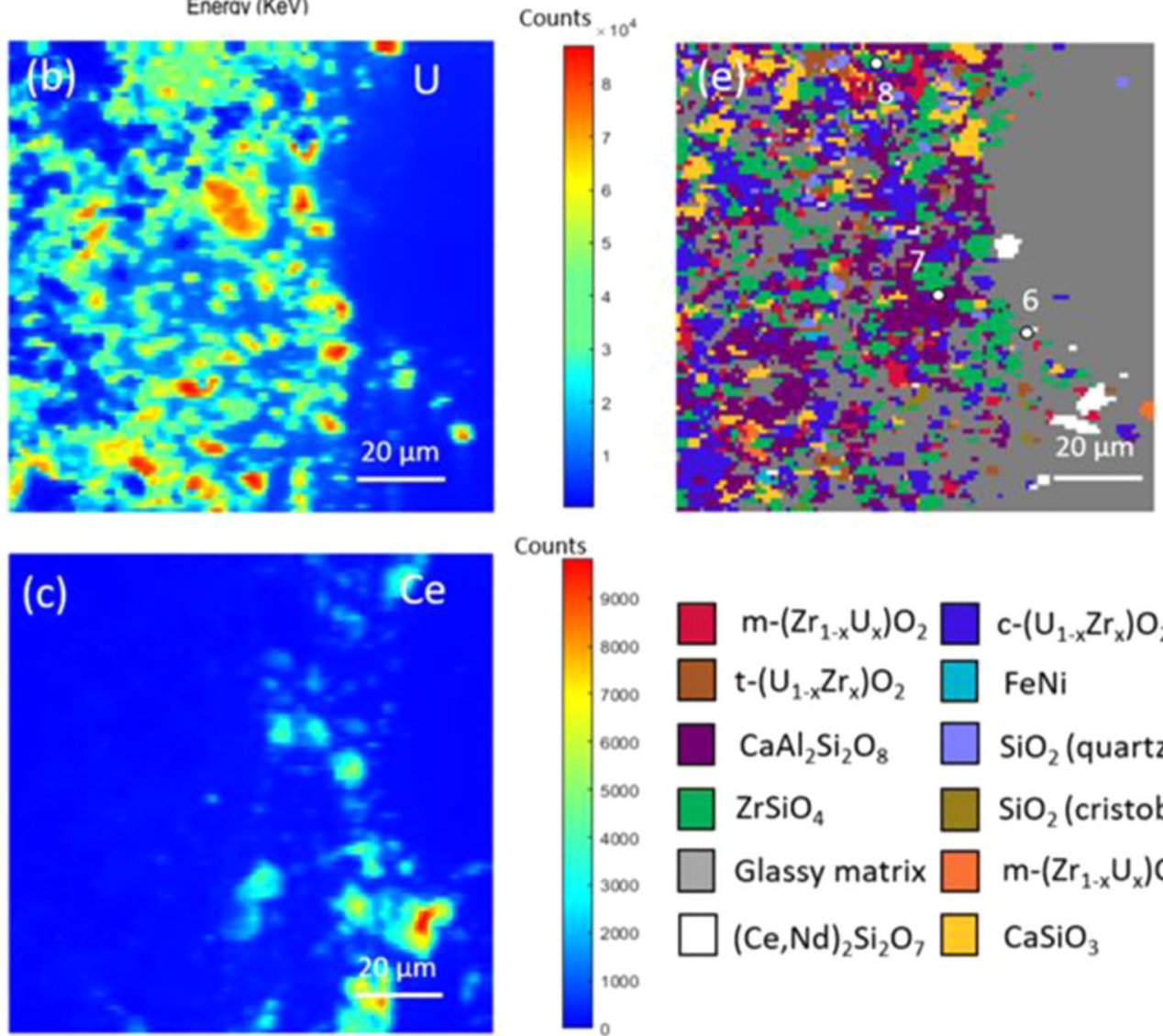

Counts
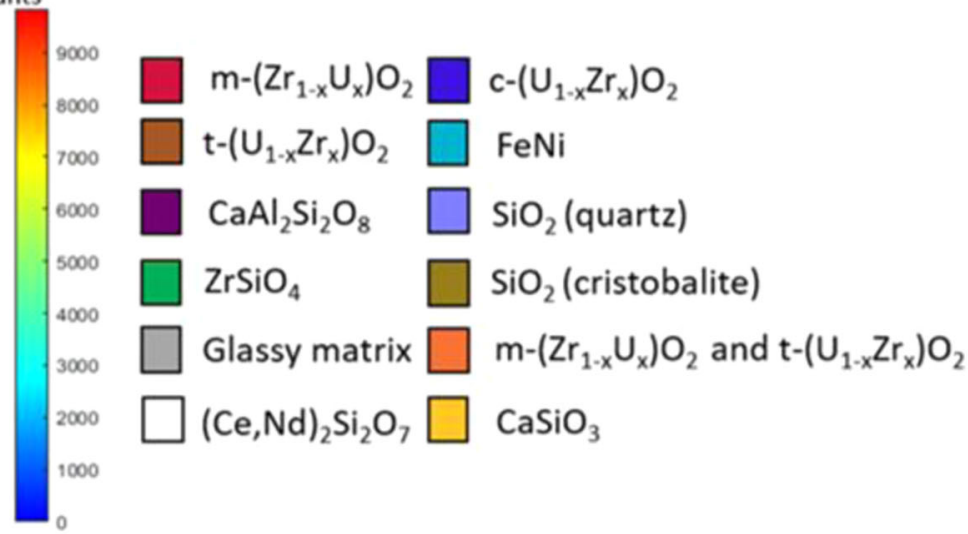

Fig. 4 Micro-focus X-ray analysis of $\mathbf{M C C l}-2$. Showing a normalised and stacked XRF spectra comparing MCCl-1 and MCCI-2; distribution of $\mathbf{b}$ $\mathrm{U}$-L $\alpha$ X-ray fluorescence signal, c Ce-L $\alpha$ X-ray fluorescence signal, $\mathbf{d} \mathrm{Zr}-\mathrm{K} \alpha \mathrm{X}$-ray fluorescence signal; and e $2 \mathrm{D} \mu$-diffraction map of $\mathrm{MCCl}-2$ reconstructed from XRD patterns taken at each individual pixel in the $\mu$-XRF maps shown in $\mathbf{a}$. The white points labelled 6-8 in e indicate the locations of interest that XANES spectra were collected from, detailed in Fig. 7. Scale bar on all images is $20 \mu \mathrm{m}$.

the $\mathrm{UO}_{2}$ reference compound. The estimated oxidation states were between $4.00 \pm 0.10$ and $4.22 \pm 0.10$, indicating that $U$ was mainly present as $\mathrm{U}^{4+}$ in the different phases of the $\mathrm{U}_{1-\mathrm{x}} \mathrm{Zr}_{\mathrm{x}} \mathrm{O}_{2}$ solid solution. The whiteline of the XANES spectrum of point 8 , located in a particle of zircon, showed a slight shift to a lower energy position compared to $\mathrm{UO}_{2}$. This observation is in accordance with the predicted effect of silicate anions on the $U$ local environment and XANES spectra, and is in good agreement with the $U L_{3}$ edge XANES of the reference compound $\mathrm{USiO}_{4}$, coffinite, which is the U-end member of zircon $\left(\mathrm{ZrSiO}_{4}\right)$. In contrast, the $U L_{3} \mu$-XANES spectrum of $U$ within the glass matrix (points 3 and 6 ) displayed a clear shift of the whiteline to slightly higher energy, relating to an estimated oxidation state of $4.32 \pm$ 0.10 and $4.37 \pm 0.10$. The variation of average $U$ oxidation states within the glass matrix and crystalline phases of simulant $\mathrm{MCCl}$ products are similar to our previous study of Chernobyl LFCM simulants ${ }^{17}$. Given that corrosion and formation of U-containing secondary phases ${ }^{27-30}$, involving changes of $U$ oxidation state, has occurred during the last 35 years for Chernobyl LFCMs, this observation might be useful for prediction and further management of Fukushima $\mathrm{MCCl}$ products.

Representative crystallites of $c-\left(U_{1-x} Z_{x}\right) O_{2}$ and $\mathrm{Zr}_{1-x} \mathrm{U}_{x} \mathrm{SiO}_{4}$ were further analysed by fitting of the $U L_{3}$ Extended $X$-ray Absorption Fine Structure (EXAFS), as shown in Fig. 8 . The $k^{3}$-weighted EXAFS 

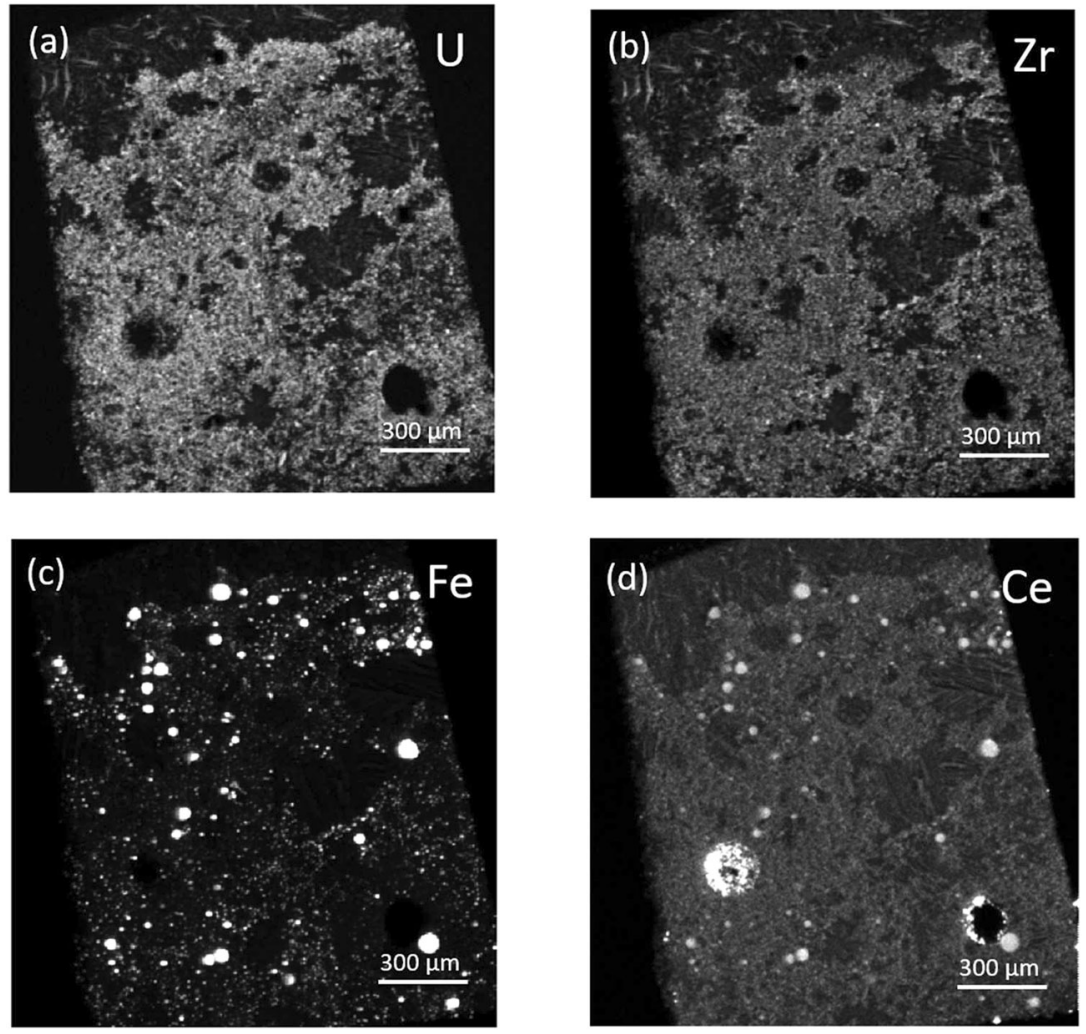

Fig. 5 Micro-focus XRF maps of MCCI-3. Showing distribution of a U-L $\alpha, \mathbf{b}$ Zr-K $\alpha, \mathbf{c}$ Fe-K $\alpha$ and $\mathbf{d}$ Ce-L $\alpha$ fluorescence signals. White regions indicate areas of high concentration, while black areas indicate regions with no concentration. Scale bar on all images is $300 \mu \mathrm{m}$.
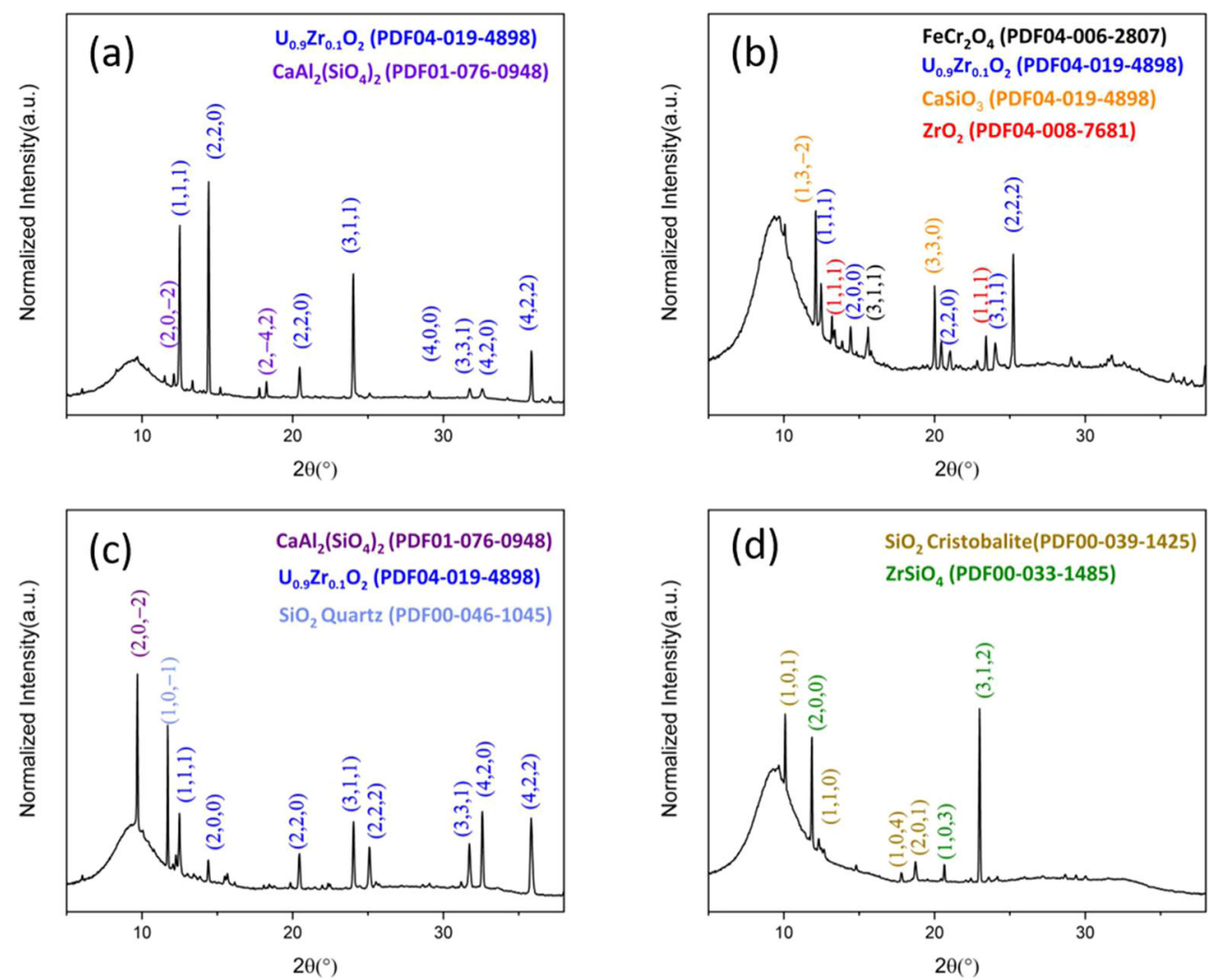

Fig. 6 Single pixel $\boldsymbol{\mu}$-diffraction patterns of silicate minerals present in $\mathbf{M C C l}$. a anorthite; $\mathbf{b} \mathrm{CaSiO}_{3} ; \mathbf{c ~} \mathrm{SiO}_{2}-\mathrm{quartz}$ and $\mathbf{d ~ S i O}{ }_{2}-\mathrm{Cristobalite}$ 

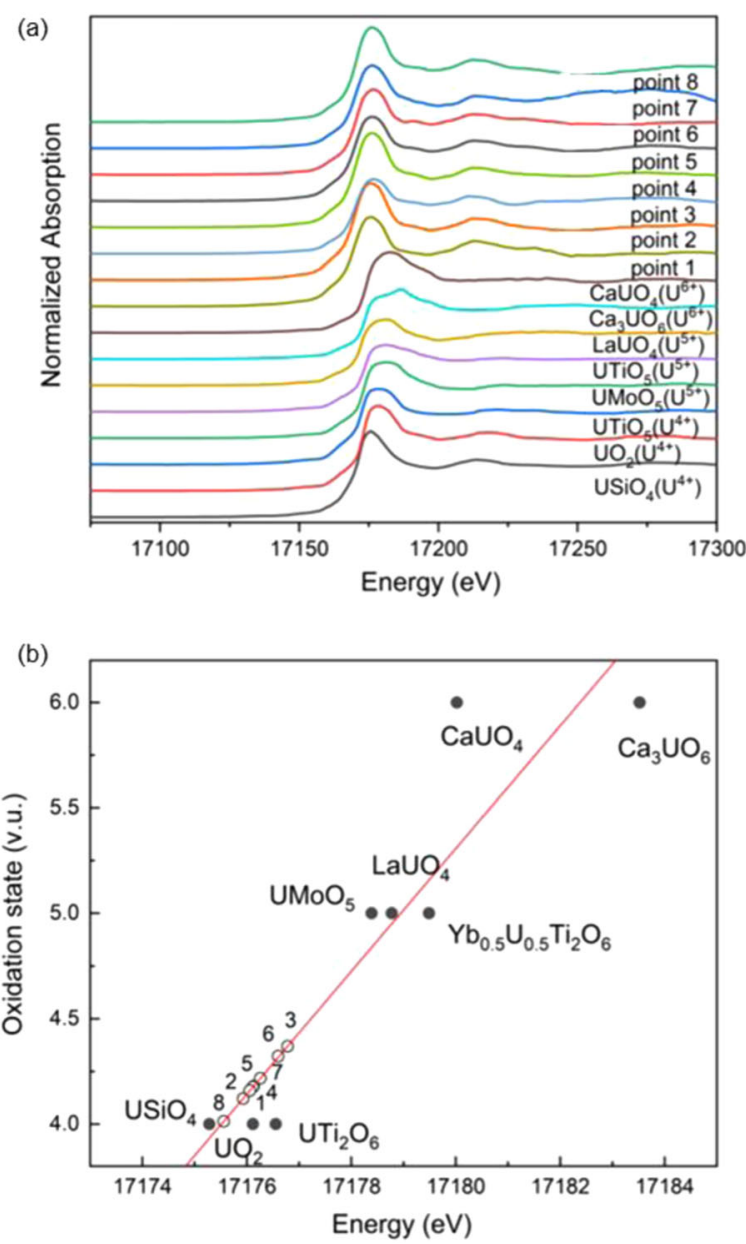

Fig. $7 \mu$-focus $U L_{3}$ edge X-ray Absorption Near Edge Spectroscopy ( $\mu$-XANES) spectra of simulant $\mathrm{MCCl}-1$ and $\mathrm{MCCl}-2$. Showing a XANES spectra of $U$ reference compounds and representative crystalline phases; and $\mathbf{b}$ average $U$ oxidation states of points located on the sample (open circles), compared with a range of $U$ reference compounds of known oxidation state (filled circles, labelled) as a function of X-ray energy.

spectra and corresponding Fourier transform (FT) were fit as shown in Supplementary Table 1 and Fig. 8 . The best fit of the spectrum of $\mathrm{c}-\left(\mathrm{U}_{1-\mathrm{x}} \mathrm{Zr}_{\mathrm{x}}\right) \mathrm{O}_{2}$ included a single $\mathrm{O}$ shell (8-fold coordination) with distance $2.32 \pm 0.01 \AA$, shorter than that of undoped $\mathrm{UO}_{2}(2.37 \AA)^{31}$. The spectrum of $\mathrm{Zr}_{1-x} \mathrm{U}_{\mathrm{x}} \mathrm{SiO}_{4}$ was fit with two shells of $\mathrm{O}: 4$ shorter bonds $(2.27 \pm 0.01 \AA)$ and 4 longer bonds $(2.43 \pm 0.01 \AA)$, slightly shorter compared to those determined in previous reports of the $\mathrm{U}$ coordination environment in $\mathrm{USiO}_{4}{ }^{32}$. These results are in good agreement with the observation made from analysis of $\mu$-XRD patterns that the presence of $\mathrm{Zr}^{4+}$ contributed to a unit cell contraction in both structures. This effect was also observed in a previous study that included EXAFS fitting of the spectra of crystallites in simulant Chernobyl LFCM materials ${ }^{17}$. Compared to $\mathrm{Zr}^{4+}$, the effect of $\mathrm{Ce}^{3 / 4+}$ incorporation within the structure is expected to be less significant due to the smaller ionic radius difference and lower concentration. The $U$ bond valence sums of the crystallites examined were estimated as 4.3 v.u. and 4.1 v.u. respectively, consistent with the average oxidation states estimated by analysis of XANES spectra.

Uranium and Fe showed a close spatial association, which was investigated further by $\mu$-XANES analysis performed on the $\mathrm{MCCl}-3$ sample, as shown in Fig. 9. The $U L_{3}$ edge XANES spectra within Fe-rich regions had no significant energy shift of the whiteline when compared to the $\mathrm{UO}_{2}$ reference compound. This suggests that $\mathrm{U}$ predominantly presented as $\mathrm{U}^{4+}$ with an average oxidation state of $3.98 \pm 0.10$. This was slightly lower than $U$ oxidation states in equivalent, but Fe-poor, regions in $\mathrm{MCCl}-1$ and $\mathrm{MCCl}-2$, indicating that the presence and oxidation of $\mathrm{Fe}$ effectively maintained $\mathrm{U}$ as $\mathrm{U}^{4+}$.

\section{Distribution and local coordination chemistry of Pu surrogate in simulant $\mathrm{MCCl}$}

The distribution and local chemistry of the Pu surrogate, Ce, was investigated to understand the potential distribution of $\mathrm{Pu}$ in $\mathrm{MCCl}$. In MCCl-3, Ce was ubiquitous in the sample (Fig. 10a, b). It was also found to be closely associated with Fe-rich regions and $\mathrm{c}-\mathrm{UO}_{2}$ particles, and was observed to concentrate at the inner surface of pores (Fig. 10c). In $\mathrm{MCCl}-2$, similar behaviour was apparent, with Ce observed to occur in two distinct phases: (1) as the Ce-silicate phase, percleveite $\mathrm{Ce}_{2} \mathrm{Si}_{2} \mathrm{O}_{7}$ (PDF \#00-048-1588), also containing $\mathrm{Nd}$ in $\mathrm{MCCl}-1$ and $\mathrm{MCCl}-2$, where Ce exists as $\mathrm{Ce}^{3+}$, which was located in regions at the interface between crystallites of zircon and the glass matrix (Figs. 4e and 10e); and (2) dissolved into the $\mathrm{UO}_{2}$ matrix, with no other Ce-bearing phases observed.

Percleveite was most likely produced by the reaction between the $\mathrm{U}-\mathrm{Zr}-\mathrm{Ce}-(\mathrm{Nd})-\mathrm{O}$ melt that had been depleted in $\mathrm{U}$ and $\mathrm{Zr}$ through the formation of crystallites, and a silicate melt. This is consistent with the spatial location between zircon and the glass matrix (Fig. 4e), and with the previously reported phase behaviour of the $\mathrm{CeO}_{2}-\mathrm{SiO}_{2}$ binary system at high temperature in a reducing atmosphere ${ }^{33}$. Under reducing conditions, $\mathrm{Ce}^{4+}$ can be fully reduced to $\mathrm{Ce}^{3+}$, which has significantly higher solubility in silicate glasses compared to $\mathrm{Ce}^{4+34}$. This enhanced solubility likely stabilised $\mathrm{Ce}^{3+}$ within the melt, which subsequently crystallised percleviete. In $\mathrm{MCCl}-3$, this phase was more prevalent throughout the matrix due to the higher concentration of $\mathrm{Ce}$. With the increase in Ce content, the formation of $\mathrm{Ce}_{2} \mathrm{Si}_{2} \mathrm{O}_{7}$ and $\mathrm{c}-\mathrm{ZrO}_{2}$, instead of zircon, $\mathrm{t}-\mathrm{ZrO}_{2}$ and $\mathrm{m}-\mathrm{ZrO}_{2}$, dominated in the $(\mathrm{Zr}, \mathrm{Ce}) \mathrm{O}_{2}$ and $(\mathrm{Zr}, \mathrm{Ce}) \mathrm{SiO}_{4}$ double-phase ceramics system ${ }^{35}$. At the high reaction temperature with the reducing atmosphere, the reductive formation of $\mathrm{Ce}_{2} \mathrm{Si}_{2} \mathrm{O}_{7}$ was enhanced ${ }^{36}$.

This interpretation is further supported by XANES analysis of the $\mathrm{Ce} \mathrm{L}_{3}$ edge obtained at a range of points in the sample of $\mathrm{MCCl}-3$ (Fig. 11), which showed that the majority of $\mathrm{Ce}$ in the striated matrix was present as $\mathrm{Ce}^{3+}$, with whiteline energies close to that of $\mathrm{CePO}_{4}$, the $\mathrm{Ce}^{3+}$ reference compound (see Fig. $11 \mathrm{a}$ ). This is a consequence of (i) the presence of $\mathrm{Ce}^{3+}$ in the starting $(\mathrm{U}, \mathrm{Ce}, \mathrm{Nd}$, $\mathrm{Zr} \mathrm{O}_{2}$ material, which was prepared under highly reducing conditions; and (ii) the reducing conditions applied during the $\mathrm{MCCl}$ simulant synthesis. The average oxidation states of $\mathrm{Ce}$ were estimated to be $3.02 \pm 0.05$ in the presence of Fe-rich particles (Ce point 3 and Ce point 4) and $3.12 \pm 0.05$ in the presence of U-rich particles (Ce point 5, Ce point 6 and Ce point 7). The Ce located in the interior of pores (Ce point 8 and Ce point 9 ) was in the form of $\mathrm{Ce}_{2} \mathrm{Si}_{2} \mathrm{O}_{7}$, as identified by $\mu$-XRD (see Fig. $10 \mathrm{~d}$ ), with an average oxidation state of $3.04 \pm 0.05$. The $k^{3}$-weighted Extended X-ray Absorption Fine Structure (EXAFS) spectra and corresponding Fourier transform (FT) were fit, utilising $\mathrm{Ce}_{2} \mathrm{Si}_{2} \mathrm{O}_{7}$ as the initial structural model (Fig. 11 and Supplementary Table 1). The fitted path lengths were in reasonable agreement with the reported crystal structure of synthetic $\mathrm{Ce}_{2} \mathrm{Si}_{2} \mathrm{O}_{7}{ }^{37}$. The average $\mathrm{Ce}-\mathrm{O}$ bond distance of Ce point 2 was shorter than that of Ce point 4 , which could be associated with a distortion of the tetragonal structure caused by the presence of $\mathrm{Ce}^{4+}$ with a smaller ionic radius $(0.97 \AA)$ compared to $\mathrm{Ce}^{3+}(1.14 \AA)$.

The presence (or absence) of phases containing $\mathrm{Fe}^{0}$ (metallic Fe$\mathrm{Ni}$ particles) seemed to influence the Ce oxidation state in some locations. $\mathrm{Ce}^{3+}$ was observed in areas where Fe-rich particles persisted, however, where Fe was absent, there was a small fraction of $\mathrm{Ce}^{4+}$. For example, the XANES spectrum of Ce point 5 , which was located in a $c_{-}\left(U_{1-x} Z_{x}\right) O_{2}$ crystallite and not close to 

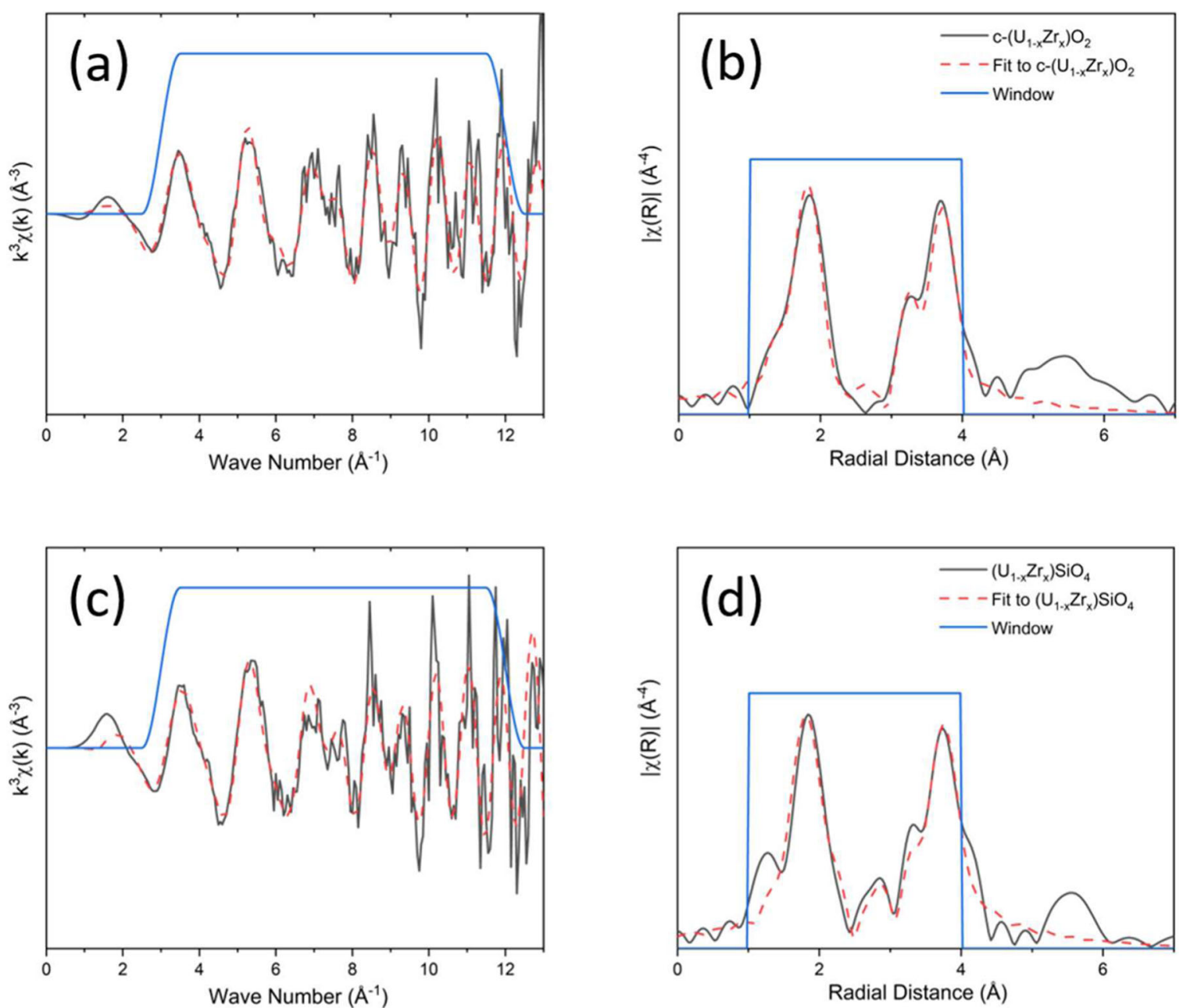

Fig. 8 Local coordination analysis of $U$ in simulant MCCI-3 determined by $\boldsymbol{\mu}$-EXAFS analysis. Showing the $U L_{3}$ spectra and model fit of a $(\mathrm{U}, \mathrm{Zr}) \mathrm{O}_{2} \mathrm{k}^{3}$ - weighted $\mu$-EXAFS and $\mathbf{b} \mu$-EXAFS in radial space; and $\mathbf{c}(\mathrm{U}, \mathrm{Zr}) \mathrm{SiO}_{4} \mathrm{k}^{3}$ - weighted $\mu$-EXAFS and $\mathbf{d} \mu$-EXAFS in radial space.

Fe-rich crystallite, had a small shoulder at approximately $5740 \mathrm{eV}$ (after the first major peak), close to the energy position of the second major peak of $\mathrm{CeO}_{2}$, and linear combination analysis revealed that up to $12 \pm 4 \% \mathrm{Ce}^{4+}$ was present. Therefore, localised heterogeneity in the partial pressure of oxygen during the simulant $\mathrm{MCCl}$ cooling, due to the presence (or absence) of stainless steel, may play a role in controlling the localised Ce oxidation state, influencing its partitioning into oxide $\left(\mathrm{as} \mathrm{Ce}^{4+}\right)$ or silicate $\left(\right.$ as $\mathrm{Ce}^{3+}$ ) phases.

\section{Efficacy of $\mathrm{MCCl}$ materials to simulate $1 \mathrm{~F}$ materials}

Comparing the analysis of the $\mathrm{MCCl}$ simulants investigated here with those of previous simulant studies (e.g. VULCANO) ${ }^{10,19}$, it is apparent that the major abundant crystalline phases and microstructures were observed to be similar. The fact that the materials in the present study were prepared on a small scale (gram-sized batches), yet yielded the same information as large scale ( $\sim 50-\mathrm{kg}$-sized batches) experiments, allowed for a range of variation in chemical composition to be easily investigated. For example, several enhancements on previous studies have been made in the present study: the method of $\mathrm{Zr}$ addition was varied to be more representative of the melt conditions at the time of the accident; Ce was incorporated as a surrogate for $\mathrm{Pu}$ and; multi-modal $\mu$-focus $\mathrm{X}$-ray analysis was applied to examine the minor phases and redox behaviours otherwise undetected by bulk analysis methods. The latter is significant from the perspective of studying real $\mathrm{MCCl}$ material once it becomes available, since any such samples will be highly radioactive and challenging to study. The application of $\mu$-focus $X$-ray chemical techniques, on sub-mm sized samples, will allow compositional, phase and speciation analysis of $\mathrm{MCCl}$, that can be translated to understand the larger volume of $\mathrm{MCCl}$ within the $1 \mathrm{~F}$ reactor units, as validated by the present study and its agreement with large-scale $\mathrm{MCCl}$ simulant synthesis.

Comparing the behaviour of $\mathrm{MCCl}-1, \mathrm{MCCl}-2$ and $\mathrm{MCCl}-3$, in which the $\mathrm{Zr}$ addition method varied, being added as either $\mathrm{ZrO}_{2}$ only $(\mathrm{MCCl}-1)$, or as in solid solution with $\mathrm{U}-(\mathrm{Ce}, \mathrm{Nd}) \mathrm{O}_{2}$ with additional $\mathrm{ZrO}_{2}(\mathrm{MCCl}-2$ and $\mathrm{MCCl}-3)$ (Table 1), it is clear that there is no real difference in the phase assemblages as a result of the way in which Zr was added; however, it had an effect on the generation of $\mathrm{U}$-containing zircon. $\mathrm{ZrO}_{2}$ addition, rather than the total amount of $\mathrm{Zr}$, promotes zircon formation, as it tends to form more $\mathrm{Zr}$ rich $(\mathrm{Zr}, \mathrm{U}) \mathrm{O}_{2}$ compared to $(\mathrm{U}, \mathrm{Zr}) \mathrm{O}_{2}$ solid solution phases.

Although the chemical behaviour of $\mathrm{Ce}$ is similar to that of $\mathrm{Pu}$ in many cases, the mechanisms of Pu-(U)-O-Si phase formation in environments comparable to those investigated may not be entirely analogous to those of $\mathrm{Ce}-(\mathrm{U})-\mathrm{O}-\mathrm{Si}$. Within the mixed oxide fuel of $1 \mathrm{~F}$ Unit 3, $\mathrm{Pu}$ was initially present as $\mathrm{Pu}^{4+}$ oxide in solid solution with $\mathrm{UO}_{2}$. Under reducing conditions, $\mathrm{CeO}_{2}$ reduces more readily than $\mathrm{PuO}_{2}$ (with $\mathrm{O} / \mathrm{M}<2$ ), so although $\mathrm{Ce}^{3+}$ was identified in the present study, $\mathrm{Pu}^{3+}$ may not necessarily occur in real $\mathrm{MCCl}$. However, the reaction between $\mathrm{PuO}_{2}$ and $\mathrm{SiO}_{2}$ has previously been reported to form Pu-percleveite $\left(\mathrm{Pu}_{2} \mathrm{Si}_{2} \mathrm{O}_{7}\right)$ in compositional 

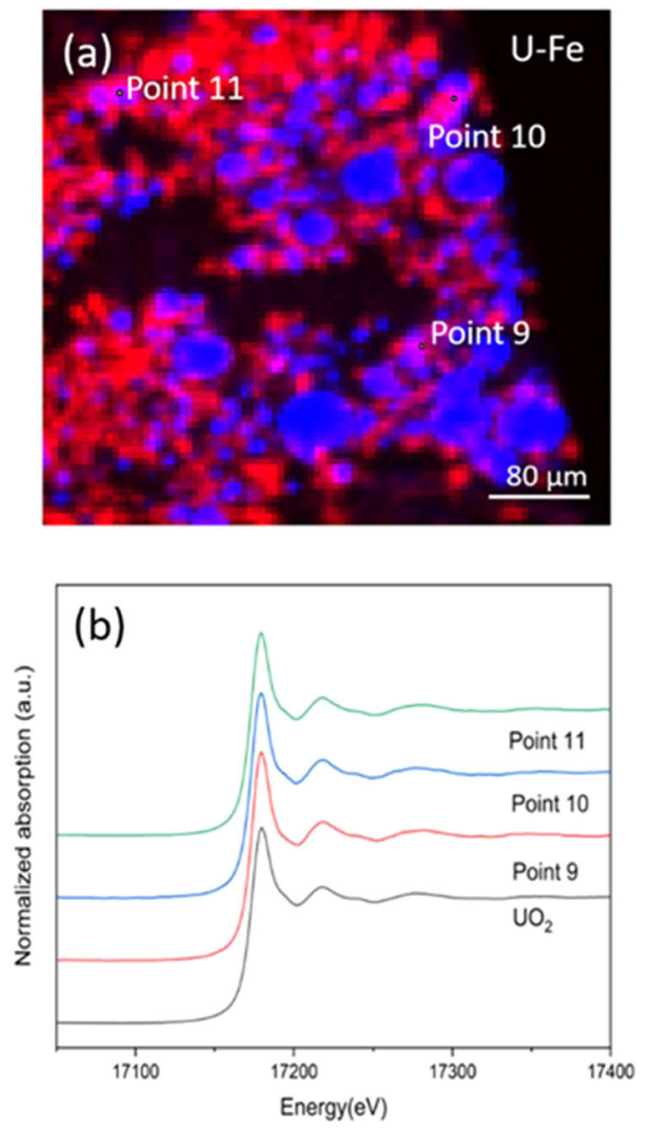

Fig. $9 \mu$-focus $X$-ray analysis of $\mathbf{M C C l}-3$. Showing a the correlation map of the distribution of U-L $\alpha$ (red) and Fe-K $\alpha$ (blue); and $\mathbf{b}$ corresponding $U L_{3}$ edge $\mu$-XANES spectra of points in a. Scale bar of a is $80 \mu \mathrm{m}$

ranges that contain particularly high $\mathrm{SiO}_{2}$ activities ${ }^{23,38}$. Moreover, $\mathrm{Pu}$ cations exhibit similar solubility to $\mathrm{Ce}$ in glasses, i.e., $\mathrm{Pu}$ is significantly more soluble as $\mathrm{Pu}^{3+}$ than $\mathrm{Pu}^{4+}$. As such, the presence of Pu-bearing silicates in real $\mathrm{MCCl}$ seems plausible, should the redox environment be sufficient to promote reduction of $\mathrm{Pu}^{4+}$ to $\mathrm{Pu}^{3+}$.

In the present study we also find tentative evidence for $\mathrm{Ce}$ substitution into the zircon structure (see Supplementary Fig. 6). $\mathrm{Sm}^{3+}$ incorporation has been reported in zircon-formed Chernobyl LFCMs ${ }^{39}$ and it has been shown that a small amount of $\mathrm{Pu}^{3+}$ may be incorporated into the zircon structure. For example, computational modelling of the Pu-zircon system suggested that a defect cluster consisting of two near-neighbour $\mathrm{Pu}^{3+}$ centres (located on the Zr site) with a closely associated oxygen vacancy charge-ensuring charge neutrality can occur ${ }^{40}$. This substitution was further suggested to be charge compensated by oxygen vacancies, with an oxygen vacancy for two $\mathrm{Pu}^{3+}$ substitutions ${ }^{41}$. Once again, should the redox environment be sufficient to promote reduction of $\mathrm{Pu}^{4+}$ to $\mathrm{Pu}^{3+}$, and sufficient $\mathrm{Zr}$ present to promote crystallisation of zircon, the presence of Pu-containing zircon in $1 \mathrm{~F}$ Unit 3 is conceivable.

\section{METHODS}

\section{Materials and synthesis}

The chemical composition of $\mathrm{MCCl}$ within $1 \mathrm{~F}$ reactor units $1-3$ is currently unknown since the collection of this material is not yet possible, limited by the high levels of radiation and radioactivity, and inaccessibility of the $\mathrm{MCCl}$. The batched compositions of simulant $\mathrm{MCCl}$ were based on estimations of the relative proportions of core materials and concrete, previously reported in the literature and through discussion with personnel at the Japan Atomic Energy Agency (CLADS) $)^{8,18}$.

The as-batched reagent stoichiometry included $(\mathrm{U}, \mathrm{Zr}, \mathrm{Nd}, \mathrm{Ce}) \mathrm{O}_{2}$ as an oxidised fuel/cladding surrogate, $\mathrm{SiO}_{2}, \mathrm{CaO}$ and $\mathrm{Al}_{2} \mathrm{O}_{3}$ as components of the sand-rich cement mortar utilised in the reactor construction, and $\mathrm{Fe}_{2} \mathrm{O}_{3}$ and 316 stainless steel $\left.\left(\mathrm{Fe} / \mathrm{Cr}_{18} / \mathrm{Ni}_{10} / \mathrm{MoO}_{3}\right)\right)$ to represent the steel components of the reactor units (Table 1$)$. Several $(\mathrm{U}, \mathrm{Nd}, \mathrm{Ce}) \mathrm{O}_{2}$ compositions were trialled as simulants of the $\mathrm{UO}_{2}$ fuel pellets, with $\mathrm{Ce}$ as surrogate for $\mathrm{Pu}$, and $\mathrm{Nd}$ as a surrogate for fission products. $\mathrm{Zr}$ was also added separately as $\mathrm{ZrO}_{2}$. $(\mathrm{U}, \mathrm{Zr}, \mathrm{Ce}, \mathrm{Nd}) \mathrm{O}_{2}$ was added to some compositions simulating the in-vessel $\mathrm{MCCl}$ formed within the reactor pressure without contacting with concretes. These solid solutions were synthesised via the ammonium hydroxide precipitation route ${ }^{42-44}$. The following reactants were used as starting materials: $\mathrm{ZrOCl}_{2} \cdot 8 \mathrm{H}_{2} \mathrm{O}(>99.9 \%), \mathrm{UO}_{2}\left(\mathrm{NO}_{3}\right)_{2} \cdot 6 \mathrm{H}_{2} \mathrm{O}$ (>99.9\%) and $\mathrm{NH}_{4} \mathrm{OH}(5 \mathrm{M}, 99.9 \%)$. All the reagents used were supplied by Sigma-Aldrich, except uranium tetrachloride solution. Because of the hygroscopic character of zirconyl salt and uranyl nitrate, it was dissolved in $1 \mathrm{M} \mathrm{HCl}$. The solutions of $\mathrm{ZrOCl}_{2}$ and $\mathrm{UO}_{2}\left(\mathrm{NO}_{3}\right)_{2}$ were mixed in the desired molar quantities and the hydroxide precursor was obtained by adding $\mathrm{NH}_{4} \mathrm{OH}$ solution ( $\mathrm{pH}$ 9). The precipitate was filtered and washed with ultrahigh quality water/isopropanol and dried at $60^{\circ} \mathrm{C}$. Calcination of this material was performed at $750{ }^{\circ} \mathrm{C}$ for $4 \mathrm{~h}\left(\mathrm{~N}_{2} / 5 \% \mathrm{H}_{2}\right)$. The resulting oxide was milled, pressed into $6 \mathrm{~mm}$ pellets and sintered at $1700^{\circ} \mathrm{C}$ for $8 \mathrm{~h}$ under a reducing atmosphere $\left(\mathrm{N}_{2} / 5 \% \mathrm{H}_{2}\right)$. The sintered pellets, characterisation of which is given in Supplementary Fig. 1, were analogous to mixed oxide fuel in their chemistry. Their heterogeneous nature differs from mixed oxide fuel, which tends to incorporate 'islands' of $\mathrm{PuO}_{2}$ within a $\mathrm{UO}_{2}$ matrix. It is assumed that all fuel material was molten at the time of the $1 \mathrm{~F}$ accident, therefore, the difference in microstructure should not significantly influence the resulting $\mathrm{MCCl}$ materials. The pellets were crushed for use in $\mathrm{MCCl}$ batches.

The reagents were mixed, milled $(30 \mathrm{~Hz}-10 \mathrm{~min})$ and then sintered in alumina crucibles under a reducing atmosphere $\left(5 \% \mathrm{H}_{2}\right.$ in $\left.95 \% \mathrm{~N}_{2}\right)$, thought to be representative of the highly reducing conditions within the reactors at the time of the accident (due the high metallic content within the reactor, in addition to the evolution of $\mathrm{H}_{2(\mathrm{~g})}$ from cladding oxidation). The furnace was heated to $1500^{\circ} \mathrm{C}$ and held for $4 \mathrm{~h}$, followed by a second dwell at $720^{\circ} \mathrm{C}$ for $72 \mathrm{~h}$ to promote crystalline grain growth that would have ensued during cooling of the molten fuel debris material. A heating and cooling rate of $3^{\circ} \mathrm{C} \mathrm{min}^{-1}$ was utilised.

\section{Bulk sample characterisation}

Powder X-ray diffraction (XRD) patterns were acquired using a Bruker D2 Phaser diffractometer operating in reflection mode (coupled $\theta-\theta$ ) at $30 \mathrm{kV}$, $10 \mathrm{~mA}$ with Ni-filtered $\mathrm{Cu} \mathrm{Ka}(\lambda=1.5418 \AA \AA)$. The scan range was $20^{\circ} \leq 2 \theta \leq$ $100^{\circ}$ with a step time of $0.3 \mathrm{~s}$ and a size step of $0.02^{\circ}$. Scanning Electron Microscopy (SEM) was undertaken using a Hitachi TM3030 operating at $15 \mathrm{kV}$ with a back-scatter electron detector and coupled Bruker Quantax 70 EDS system. Samples were prepared for SEM analysis by mounting in a cold-set epoxy resin and polishing to an optical finish with increasingly fine grades of grit paper and diamond suspension.

\section{Micro-focus X-ray analysis}

Micro-focus XRF, XAS and XRD measurements were conducted at the Swiss Light Source, Paul Scherrer Institute, Switzerland on the beamline microXAS-X05LA ${ }^{45}$. A fixed-exit double crystal monochromator (Si (111)) was used, maintaining consistent and stable beam angles and offsets for all experiments. The spot size of the monochromatic beam at the sample was tuned to $1 \mu \mathrm{m} \times 1 \mu \mathrm{m}$ by a Kirkpatrick-Baez (KB) mirror system at a fixed incident X-ray energy of $18,100 \mathrm{eV}$. Samples were prepared by mounting on a $250-\mu \mathrm{m}$ fused high purity quartz slide, before thinning and polishing to a thickness of $50 \mu \mathrm{m}$ using standard metallographic procedures. The prepared slides were mounted on a manipulator $80 \mathrm{~mm}$ behind the KB mirror. The angles and distances between detectors and samples were calibrated by measuring a silicon standard, and X-ray energy was calibrated using $\mathrm{Zr}$ and $\mathrm{Y}$ reference foils. Micro-focus XRD patterns were collected using a DECTRIS Eiger $4 \mathrm{M}$ detector within a range of $3.5-42.6^{\circ} 2 \theta$, with angular resolution of $0.02^{\circ}$ and wavelength of $0.6854(\AA)$. $\mathrm{X}$-ray fluorescence (XRF) spectra were measured simultaneously, using a $\mathrm{Si}$ drift-detector (KETEK) with $4 \%$ energy resolution. 

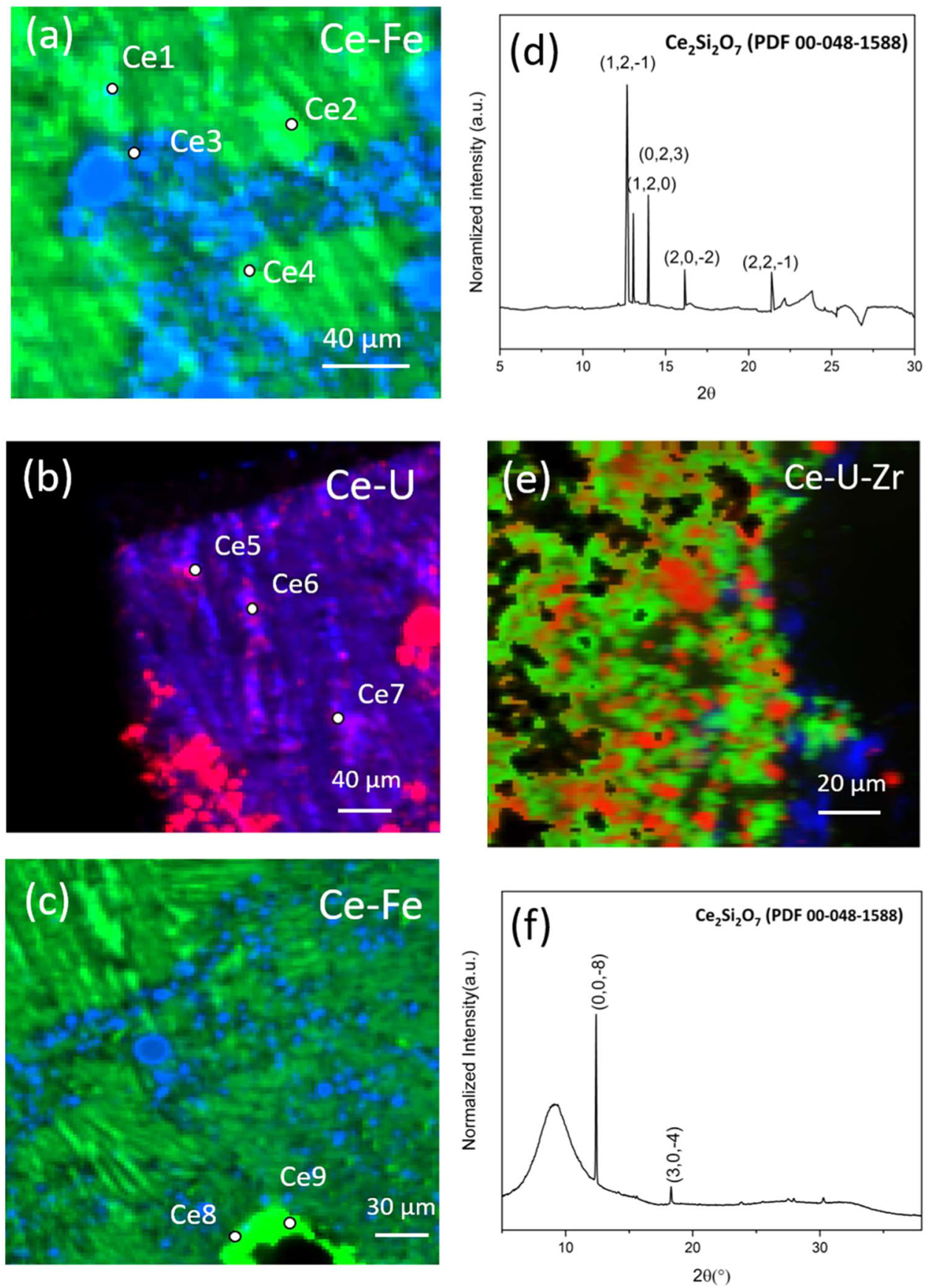

Fig. $10 \mu$-focus X-ray analysis of $\mathbf{M C C l}-2$ and $\mathbf{M C C l}-3$ Pu surrogates. Showing correlation maps obtained for $\mathrm{MCCl}-3$ of the distribution of a $\mathrm{Fe}-\mathrm{K} \alpha$ (blue) and $\mathrm{Ce}-\mathrm{L} \alpha$ (green), $\mathbf{b} \mathrm{U}-\mathrm{L} \alpha$ (blue) and $\mathrm{Ce}-\mathrm{L} \alpha$ (red) and $\mathbf{c}$ Fe-K $\alpha$ (blue) and Ce-L $\alpha$ (green), highlighting the positions of $\mu-\mathrm{XANES}$ analysis in Fig. 11; d $\mu$-XRD close to point Ce8 indexed as $\mathrm{Ce}_{2} \mathrm{Si}_{2} \mathrm{O}_{7}$ (PDF \#00-048-1588); e U-L $\alpha$ (red), Zr-Ko (green) and Ce-L $\alpha$ (blue) X-ray fluorescence signals, and $\mathbf{f}$ a single pixel $\mu$-XRD pattern indexed as $\mathrm{Ce}_{2} \mathrm{Si}_{2} \mathrm{O}_{7}$ (PDF \#00-048-1588). Scale bars are as follow: a and b $40 \mu \mathrm{m}$; c $30 \mu \mathrm{m}$; and e $20 \mu \mathrm{m}$.

Azimuthal integration of individual $2 \mathrm{D} \mu$-diffraction patterns and summation of the whole area was applied using the XRDUA software package, to construct $1 \mathrm{D}$ diffraction patterns ${ }^{46}$. The phase assemblages observed were determined by matching the observed reflection with materials previously reported in the ICDD PDF database ${ }^{47}$. The distributions and relative abundances of the elements of interest were obtained from $\mu$-XRF maps. Utilising both $\mu$-XRD and $\mu$-XRF measurements, the $2 D$ phase assemblage was reconstructed using a MATLAB script (produced in-house) that automated diffraction pattern indexing and constructed images showing the relative distribution of phases, which has been reported in detail in our previous study ${ }^{17}$.
Uranium $L_{3}$ edge XANES spectra were collected at points of interest over the energy range $17,060-17,325 \mathrm{eV}$, with an energy resolution of $0.2 \mathrm{eV}$. Energy calibration was conducted based on the $\mathrm{K}$ edge $(17,038 \mathrm{eV})$ of an $Y$ foil reference. Four repeat measurements at each point were collected in fluorescence mode and then averaged. The threshold energy $\left(E_{0}\right)$ and edge location were determined as the first inflection point and white line position of the spectra respectively. The oxidation state of $U$ has a near-linear influence on the minimum excitement energy at the $U L_{3}$ edge, with changes in effective nuclear charge causing a shift of the edge position to higher energies. To estimate the $U$ oxidation states present within the sample, a linear function was established based 

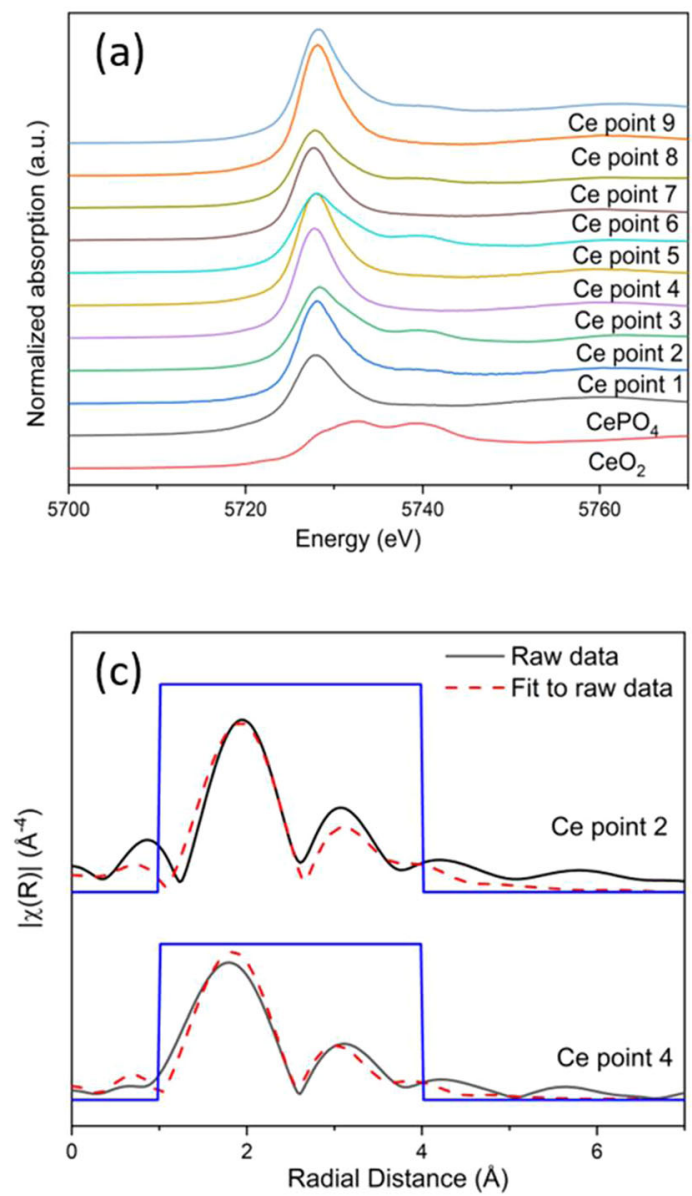
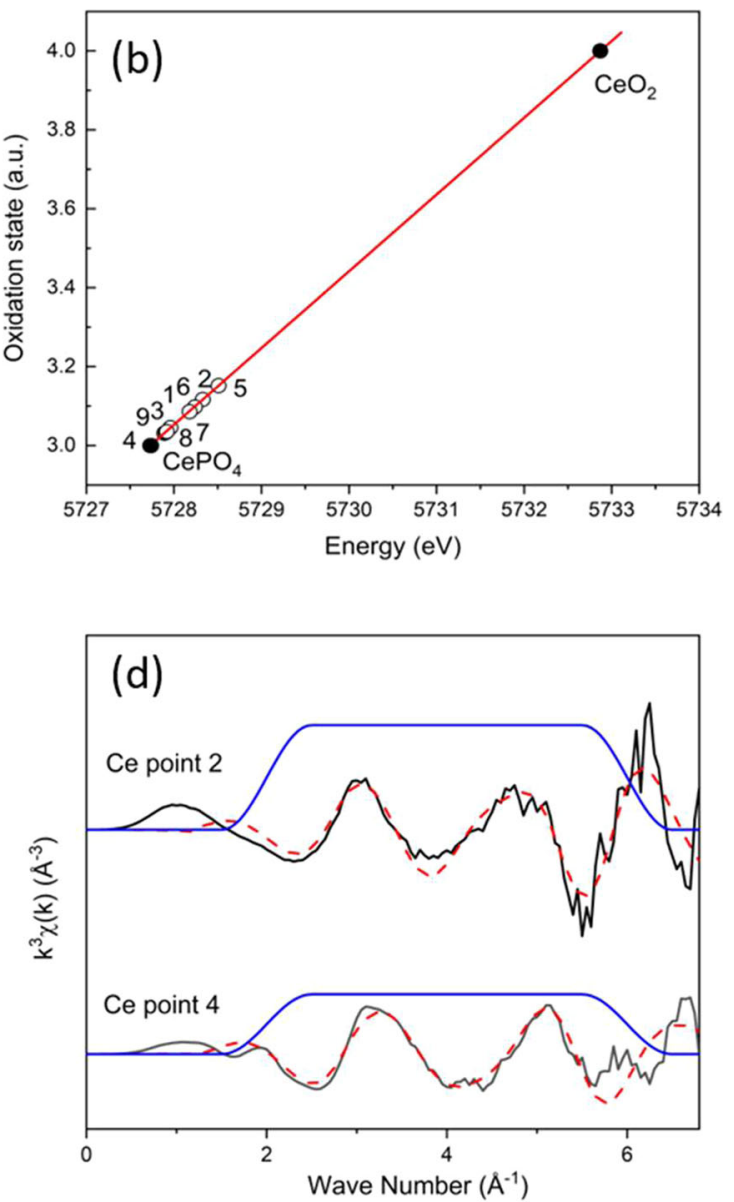

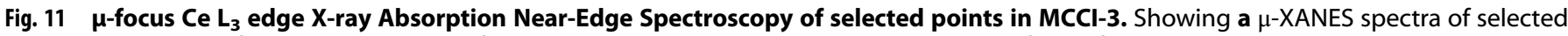
points and cerium reference compounds of known valence; $\mathbf{b}$ average Ce oxidation states inferred from spectra acquired in the sample (open circles) compared with $\mathrm{Ce}^{3+}$ and $\mathrm{Ce}^{4+}$ reference compounds (filled circles, labelled) as a function of X-ray energy; and local coordination analysis of Ce utilising fits of $\mu$-EXAFS spectra of points 2 and 4 in $c$ radial space and $\mathbf{d}$ their corresponding $k^{3}$ - weighted $\mu$-EXAFS spectra.

on $U L_{3}$ edge XANES spectra of a range of uranium-containing reference compounds, selected to give the best matches between $U$ chemical environments and electron configurations in comparison to the phases observed in the simulant corium material. Reference compounds measured included: $\mathrm{UO}_{2}\left(\mathrm{U}\right.$ oxidation state $(\mathrm{OS}) \mathrm{U}^{4+}$ and coordination number (CN) 8); $\mathrm{UO}_{3}(\mathrm{OS} 6+$ and $\mathrm{CN} 6) ; \mathrm{CaUO}_{4}(\mathrm{OS} 6+$ and $\mathrm{CN} 8) ; \mathrm{UMoO}_{5}$ (OS $5+$ and $\mathrm{CN} \mathrm{7);} \mathrm{LaUO}_{4}(\mathrm{OS} 5+$ and $\mathrm{CN} 8) ; \mathrm{UTiO}_{5}(\mathrm{OS} 6+$ and $\mathrm{CN} \mathrm{7)} ;$ $\mathrm{UTi}_{2} \mathrm{O}_{6}$ (OS $4+$ and $\mathrm{CN} 6$ ); and $\mathrm{Ca}_{3} \mathrm{UO}_{6}$ (OS 6 and $\mathrm{CN} 6$ ). XANES spectra of synthetic coffinite, $\mathrm{USiO}_{4}$ (OS $4+$ and $\mathrm{CN}$ 8) were also collected and calibrated for use as a silicate $\mathrm{U}^{4+}$ reference compound for the best description of $U$ coordination in the zircon and glass phases ${ }^{48,49}$.

Micro-focus Extended X-ray Absorption Fine Structure (EXAFS) spectra were collected at the National Synchrotron Light Source II (NSLS-II), Brookhaven National Laboratory, USA, on beamline 4BM (XFM). The measurements were taken under similar conditions as the measurements at the Swiss Light Source, for $U L_{3}$ edge XANES and EXAFS spectra. Ce $L_{3}$ edge XANES and EXAFS spectra were collected over the energy range $5525-6025 \mathrm{eV}$. Ce oxidation states were estimated using the same linear function method described above. Well characterised samples of $\mathrm{CeO}_{2}(\mathrm{OS}$ $4+$ and $\mathrm{CN} 8$ ) and $\mathrm{CePO}_{4}(\mathrm{OS} 3+$ and $\mathrm{CN}$ 8) were measured to act as reference compounds. The raw EXAFS data were normalised and a Fourier transform was applied over the $k$-range $3.0-12.0 \AA^{-1}$ for $U$ and over the $k$-range $2.0-6.0 \AA^{-1}$ for $\mathrm{Ce}$, using Athena and Artemis, components of the Demeter software package ${ }^{50}$. Scattering paths including amplitude, phase shift, mean free path and the initial path lengths were calculated by employing the FEFF code as implemented in Artemis. Fitting was conducted by fixing the amplitude at 0.95 for $\mathrm{U}$ and 0.9 for $\mathrm{Ce}$ (these values were obtained by fitting of the EXAFS spectra of $\mathrm{USiO}_{4}$ and $\mathrm{CePO}_{4}$ reference compounds), using the same Debye-Waller factors for all paths comprising the first oxygen shell, and refining the interatomic distance and coordination numbers simultaneously.

\section{DATA AVAILABILITY}

The data that support these findings are available upon reasonable request to the authors.

\section{CODE AVAILABILITY}

Matlab codes that were used to analyze the $\mu$-XRF and $\mu$-XRD are written for Matlab2018a with Signal Processing toolbox. These codes are freely available in Github (https://github.com/Hding8).

Received: 4 October 2021; Accepted: 21 December 2021; Published online: 02 February 2022

\section{REFERENCES}

1. IAEA. The fukushima daiichi accident: description and context of the accident. Fukushima Daiichi Accid. 1, 1-238 (2015).

2. Burns, P. C., Ewing, R. C. \& Navrotsky, A. Nuclear fuel in a reactor accident. Science 335, 1184-1188 (2012).

3. Nuclear Regulation Agency. Benchmark Study of the Accident at the Fukushima Daiichi Nuclear Power Plant (BSAF Project) - Phase I Summary Report, NEA/CSNI/R (2015) 18, 1-56 (2015).

4. Bogatov, S. A. et al. Formation and spread of Chernobyl lavas. Radiochemistry 50, 650-654 (2008). 
5. Pazukhin, E. M. Fuel-containing Lavas Of The Chernobyl NPP 4th Block Topography physicochemical properties and formation scenario. Radiochemistry 36, 109-154 (1994).

6. Vlasova, I. et al. Radioactivity distribution in fuel-containing materials (Chernobyl 'lava') and aerosols from the Chernobyl 'shelter'. Radiat. Meas. 83, 20-25 (2015).

7. Shiryaev, A. A. et al. Physico-chemical properties of Chernobyl lava and their destruction products. Prog. Nucl. Energy 92, 104-118 (2016).

8. Kitagaki, T., Yano, K., Ogino, H. \& Washiya, T. Thermodynamic evaluation of the solidification phase of molten core-concrete under estimated Fukushima Daiichi nuclear power plant accident conditions. J. Nucl. Mater. 486, 206-215 (2017).

9. Tanabe, F. Analyses of core melt and re-melt in the Fukushima Daiichi nuclear reactors. J. Nucl. Sci. Technol. 49, 18-36 (2012).

10. Brissonneau, L. et al. Material characterization of the VULCANO corium concrete interaction test with concrete representative of Fukushima Daiichi Nuclear Plants. J. Nucl. Mater. 528, 1-18 (2020).

11. Bonneville, H., Carenini, L. \& Barrachin, M. Core melt composition at fukushima daiichi: results of transient simulations with ASTEC. Nucl. Technol. 196, 489-498 (2016).

12. Mo, S., Ho, J., Kim, J., Kim, H. \& Naitoh, M. Experimental investigation on molten pool representing corium composition at Fukushima Daiichi nuclear power plant. J. Nucl. Mater. 478, 164-171 (2016).

13. Marra, J. C. et al. Cerium as a Surrogate in the Plutonium Immobilized Form, in Environmental Issues and Waste Management Technologies in the Ceramic and Nuclear Industries VII 2006 381-388 (Ceramic Transaction Series, Volume 132, American Ceramic Society).

14. De Almeida, L., Grandjean, S., Vigier, N. \& Patisson, F. Insights into the thermal decomposition of lanthanide(III) and actinide(III) oxalates - from neodymium and cerium to plutonium. Eur. J. Inorg. Chem. 2012, 4986-4999 (2012).

15. Zamoryanskaya, M. V. \& Burakov, B. E. Feasibility limits in using cerium as a surrogate for plutonium incorporation in zircon, zirconia and pyrochlore. MRS Proc. 663, 301 (2000).

16. Barlow, S. T. et al. Synthesis, characterisation and corrosion behaviour of simulant Chernobyl nuclear meltdown materials. npj Mater. Degrad. 4, 3 (2020).

17. Ding, H. et al. Safely probing the chemistry of Chernobyl nuclear fuel using microfocus X-ray analysis. J. Mater. Chem. A 9, 12612-12622 (2021).

18. Tanabe, F. Analysis of core melt accident in Fukushima Daiichi-unit 1 nuclear reactor. J. Nucl. Sci. Technol. 48, 1135-1139 (2011).

19. Kitagaki, T. et al. Characterization of the VULCANO test products for fuel debris removal from the Fukushima Daiichi Nuclear Power Plant. Prog. Nucl. Sci. Technol. 5, 217-220 (2018).

20. Bakardjieva, S. et al. Quality improvements of thermodynamic data applied to corium interactions for severe accident modelling in SARNET2. Ann. Nucl. Energy 74, 110-124 (2014).

21. Ushakov, S. V. et al. Solid solutions of $\mathrm{Ce}, \mathrm{U}$, and Th in zircon. Ceram. Trans. 93, 357-363 (1999).

22. Ushakov, S. V. et al. Synthesis of Ce-doped zircon by a sol-gel process. MRS Proc. 506, 281 (1997).

23. Uchida, T. et al. Phase states in the Pu-Si-O ternary system. IOP Conf. Ser. Mater. Sci. Eng. 9, 012004 (2010).

24. Journeau, C., Sudreau, F., Magne, S. \& Cognet, G. Physico-chemical analyses and solidification path reconstruction of multi-component oxidic spread melts. Mater. Sci. Eng. 299, 249-266 (2001).

25. Quaini, A. et al. Experimental contribution to the corium thermodynamic modelling - The U-Zr-Al-Ca-Si-O system. Ann. Nucl. Energy 93, 43-49 (2016).

26. Ball, R. G. J., Mignanelli, M. A., Barry, T. I. \& Gisby, J. A. The calculation of phase equilibria of oxide core-concrete. J. Nucl. Mater. 201, 238-249 (1993).

27. Ogorodnikov, B. I., Budyka, A. K. \& Khan, V. E. Specific features of radioactive aerosols in subreactor rooms of the shelter object of Chernobyl NPP. Radiochemistry 57, 652-660 (2015).

28. Burakov, B. E., Strykanova, E. E. \& Anderson, E. B. Secondary uranium minerals on the surface of chernobyl "Lava". Mater. Res. Soc. Symp. Proc. 465, 1309-1311 (1996).

29. Badovskii, V. P., Melenevskii, A. E., Morozov, Y. V., Ushakov, I. A. \& Shcherbin, V. N. Generation of radioactive dust by lava-like fuel-containing materials at the Shelter Object of Chernobyl NPP. Radiochemistry 56, 311-318 (2014).

30. Krasnov, V. A., Pazukhin, E. M., Sizov, A. A. \& Kholodiuk, A. A. Impact of open accumulations of lava-like fuel-containing materials in the CNPP shelter object on the personnel and environment. Radiochemistry 56, 439-444 (2014).

31. Shannon, R. D. Revised effective ionic radii and systematic studies of interatomic distances in halides and chalcogenides. Acta Crystallogr. Sect. A 32, 751-767 (1976).

32. Labs, S. et al. Synthesis of coffinite, USiO4, and structural investigations of UxTh(1x)SiO4 solid solutions. Environ. Sci. Technol. 48, 854-860 (2014).
33. Kepiński, L., Wołcyrz, M. \& Marchewka, M. Structure evolution of nanocrystalline $\mathrm{CeO}_{2}$ supported on silica: Effect of temperature and atmosphere. J. Solid State Chem. 168, 110-118 (2002).

34. Deschanels, X., Cachia, J. N., Lopez, C. \& Peuget, S. Influence of processing conditions on the glass-crystal transition into borosilicate glasses. International Conference On Nuclear Chemistry For Sustainable Fuel Cycles's 1-7 (ATALANTE, 2008).

35. Ding, Y. et al. Phase and microstructure evolution of $0.2 \mathrm{Zr}_{1-\mathrm{x}} \mathrm{Ce}_{\mathrm{x}} \mathrm{O}_{2} / \mathrm{Zr}_{1-\mathrm{y}} \mathrm{Ce}_{\mathrm{y}} \mathrm{SiO}_{4}$ $(0 \leq x+y \leq 1)$ ceramics designed to immobilize tetravalent actinides. J. Nucl. Mater. 539, 152318 (2020).

36. Strzelecki, A. C. et al. High-temperature thermodynamics of cerium silicates, A- $\mathrm{Ce}_{2} \mathrm{Si}_{2} \mathrm{O}_{7}$, and $\mathrm{Ce}_{4.67}\left(\mathrm{SiO}_{4}\right)_{3} \mathrm{O}$. ACS Earth Space Chem. 4, 2129-2143 (2020).

37. Deng, B. \& Ibers, J. A. Dicerium disilicate, $\mathrm{Ce}_{2}\left[\mathrm{Si}_{2} \mathrm{O}_{7}\right]$. Acta Crystallogr. Sect. E Struct. Rep. Online 61, 76-78 (2005).

38. Guéneau, C. et al. Thermodynamic modelling of advanced oxide and carbide nuclear fuels: description of the U- Pu - O - C systems. J. Nucl. Mater. 419, 145-167 (2011).

39. Shiryaev, A. A. et al. Study of mineral grains extracted from the Chernobyl "lava". Mineral. Petrol. 114, 489-499 (2020).

40. Bian, L. et al. DFT and two-dimensional correlation analysis methods for evaluating the $\mathrm{Pu}^{3+}-\mathrm{Pu}^{4+}$ electronic transition of plutonium-doped zircon. J. Hazard. Mater. 294, 47-56 (2015).

41. Williford, R. E., Begg, B. D., Weber, W. J. \& Hess, N. J. Computer simulation of $\mathrm{Pu}^{3+}$ and $\mathrm{Pu}^{4+}$ substitutions in zircon. J. Nucl. Mater. 278, 207-211 (2000).

42. Duh, J. G., Dai, H. T. \& Hsu, W. Y. Synthesis and sintering behaviour in $\mathrm{CeO}_{2}-\mathrm{ZrO}_{2}$ ceramics. J. Mater. Sci. 23, 2786-2791 (1988).

43. Settu, T. \& Gobinathan, R. Synthesis and characterization of $\mathrm{Y}_{2} \mathrm{O}_{3}-\mathrm{ZrO}_{2}$ and $\mathrm{Y}_{2} \mathrm{O}_{3}-$ $\mathrm{CeO}_{2}-\mathrm{ZrO}_{2}$ precursor powders. J. Eur. Ceram. Soc. 16, 1309-1318 (1996).

44. Masui, T., Minami, K., Koyabu, K. \& Today, N. Synthesis and characterization of new promoters based on $\mathrm{CeO}_{2}-\mathrm{ZrO}_{2}-\mathrm{Bi}_{2} \mathrm{O}_{3}$ for automotive exhaust catalysts. Catal. Today 117, 187-192 (2006).

45. Borca, C. N. et al. The microXAS beamline at the Swiss Light Source: towards nano-scale imaging. J. Phys. Conf. Ser. 186, 012003 (2009).

46. De Nolf, W., Vanmeert, F. \& Janssens, K. XRDUA: crystalline phase distribution maps by two-dimensional scanning and tomographic (micro) X-ray powder diffraction research papers. Appl. Crystallogr. 47, 1107-1117 (2014).

47. Bergerhoff, G. \& Brown, I. D. Inorganic Crystal Structure Database, in Crystallographic Databases, 77-95 (International Union of Crystallography, Bonn/Cambridge/Chester, 1987).

48. Guo, X. et al. Thermodynamics of formation of coffinite, USiO ${ }_{4}$. Proc. Natl Acad. Sci. USA 112, 6551-6555 (2015).

49. Szenknect, S. et al. Coffinite formation from $\cup_{2+x}$. Sci. Rep. 10, 1-10 (2020).

50. Ravel, B. \& Newville, M. ATHENA, ARTEMIS, HEPHAESTUS: data analysis for X-ray absorption spectroscopy using IFEFFIT. J. Synchrotron Radiat. 12, 537-541 (2005).

51. Hyatt, N. C. et al. The HADES facility for high activity decommissioning engineering \& science: part of the UK national nuclear user facility. IOP Conf. Ser. Mater. Sci. Eng. 818, 012022 (2020).

\section{ACKNOWLEDGEMENTS}

This work was funded by the UK Engineering and Physical Science Research Council (EPSRC) under grant agreement numbers EP/N017374/1, EP/R01924X/1, EP/S020659/ 1 and EP/S01019X/1. M.C.D.W. is grateful to the Nuclear Decommissioning Authority for PhD sponsorship. This research utilised the HADES/MIDAS facility at the University of Sheffield established with financial support from EPSRC and BEIS, under grant EP/ T011424/151. The authors would like to thank the Paul Scherrer Institut, Villigen, Switzerland for provision of synchrotron radiation beamtime at beamline $\mathrm{X} 05$ of the Swiss Light Source, and in particular Dario Ferreira Sanchez for his assistance. This research also utilised beamline 4-BM of the National Synchrotron Light Source II, a U. S. Department of Energy (DOE) Office of Science User Facility operated for the DOE Office of Science by Brookhaven National Laboratory under Contract No. DESC0012704. We would like to thank our Japanese collaborators within the EPSRCMEXT CHIMP project, at The University of Tokyo and JAEA, for fruitful discussions about $\mathrm{MCCl}$ materials.

\section{AUTHOR CONTRIBUTIONS}

H.D. - data collection, formal analysis and original draft preparation. C.G. - data collection, formal analysis and original draft preparation. M.D.W. - original draft preparation, reviewing and editing. L.M. - data collection and formal analysis. M.S. data collection and formal analysis. D.G. - data collection, formal analysis, reviewing and editing. R.T. - data collection and formal analysis. S.N. - data collection and formal analysis. S.S. - data collection and formal analysis. T.S. - funding acquisition, 
supervision, reviewing and editing. H.P. - formal analysis, reviewing and editing. N.C.H. - funding acquisition, supervision, formal analysis, reviewing and editing C.L.C. - funding acquisition, supervision, formal analysis, reviewing and editing.

\section{COMPETING INTERESTS}

The authors declare no competing interests.

\section{ADDITIONAL INFORMATION}

Supplementary information The online version contains supplementary material available at https://doi.org/10.1038/s41529-022-00219-3.

Correspondence and requests for materials should be addressed to Neil C. Hyatt or Claire L. Corkhill.

Reprints and permission information is available at http://www.nature.com/ reprints
Publisher's note Springer Nature remains neutral with regard to jurisdictional claims in published maps and institutional affiliations. (i) Open Access This article is licensed under a Creative Commons Attribution 4.0 International License, which permits use, sharing, adaptation, distribution and reproduction in any medium or format, as long as you give appropriate credit to the original author(s) and the source, provide a link to the Creative Commons license, and indicate if changes were made. The images or other third party material in this article are included in the article's Creative Commons license, unless indicated otherwise in a credit line to the material. If material is not included in the article's Creative Commons license and your intended use is not permitted by statutory regulation or exceeds the permitted use, you will need to obtain permission directly from the copyright holder. To view a copy of this license, visit http://creativecommons. org/licenses/by/4.0/.

(c) The Author(s) 2022 